Universidade de Brasília

Faculdade de Tecnologia

Departamento de Engenharia Elétrica

\title{
GESTÃO DE ENERGIA ELÉTRICA NO CAMPUS DARCY RIBEIRO: RATEIO E FERRAMENTAS
}

\author{
Por \\ Alexandre Braga Menezes de Faria \\ André Duboc Rochadel
}

Orientador:

Prof. Dr. Marco Aurélio de Oliveira

Brasília/DF, Julho de 2008 
UNIVERSIDADE DE BRASILIA

Faculdade de Tecnologia

\section{Alexandre Braga Menezes de Faria}

André Duboc Rochadel

Relatório submetido como requisito parcial para obtenção

do grau de Engenheiro Eletricista

\section{Banca Examinadora}

Prof. Marco Aurélio Gonçalves de Oliveira, UnB/

Departamento de Engenharia Elétrica(Orientador)

Prof. Ivan Marques de Toledo Camargo,

UnB/Departamento de Engenharia Elétrica

Engenheira Lilian Silva de Oliveira 


\section{AGRADECIMENTOS}

Agradeço à minha tia e meu tio, pela atenção e carinho imensuráveis e por terem me apoiado durante toda a vida. Pelo papel de pais que exercem com tanta dedicação e esmero. Pelo exemplo que são como pessoas e profissionais, dos quais tenho muito orgulho.

Ao meu primo, na verdade irmão, o recém formado psicólogo Guilherme, por compartilhar sua vida, experiências e pais todo este tempo.

Aos meus irmãos, Éder e Débora, todos meus familiares e amigos, pessoas que me ajudaram e deram força.

Ao meu orientador e todos aqueles que contribuíram para a execução deste trabalho.

À minha amada, Uyara, que me suporta todos os dias.

Ao Youtube, que me fez rir mesmo quando estava aos prantos.

Não menos importante, agradeço a todos os colegas de curso que tornaram esta etapa da minha vida um evento de muita satisfação e aprendizagem.

Alexandre Braga Menezes de Faria

Agradeço aos meus pais, Marco e Sônia, e à minha família pelo incentivo e apoio sempre dados.

Aos meus amigos e colegas de curso, sem os quais certamente não chegaria tão longe.

Ao meu orientador, professor Marco Aurélio de Oliveira, por toda a ajuda e diretrizes.

À Engenheira Lilian Silva de Oliveira, cuja paciência e constante auxílio possibilitaram a finalização deste trabalho.

Às bandas The Who e The Beatles pela trilha sonora.

De antemão, destaco que me responsabilizo completamente por todas as partes corretas do presente trabalho. Qualquer dúvida sobre as demais partes favor consultar os outros colaboradores.

André Duboc Rochadel 


\section{Índice}

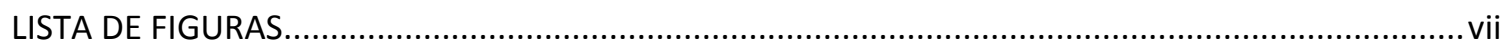

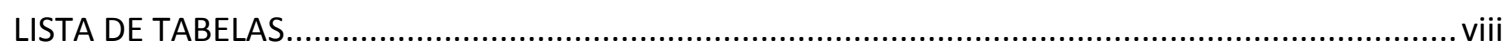

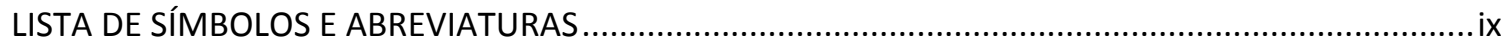

RESUMO …

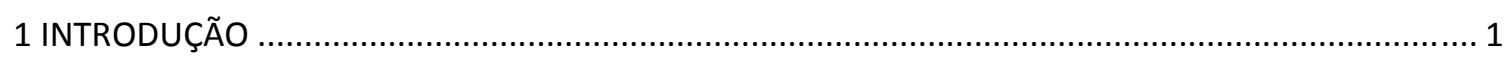

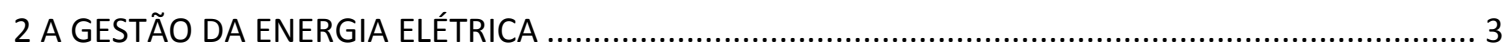

2.1 ENERGIA ELÉTRICA: EVOLUÇÃO DO CONSUMO................................................................. 3

2.2 EFEITOS DA REDUÇÃO DE CONSUMO DE ENERGIA ELÉTRICA …....................................... 4

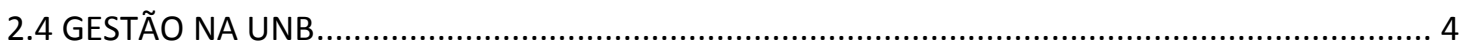

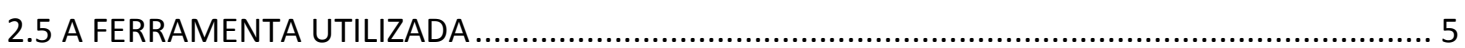

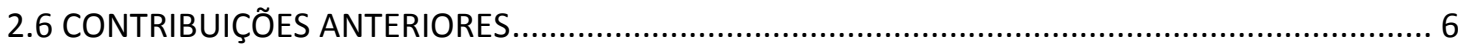

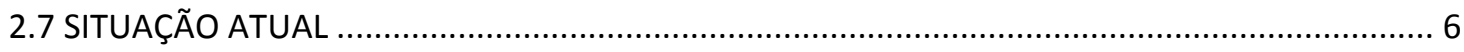

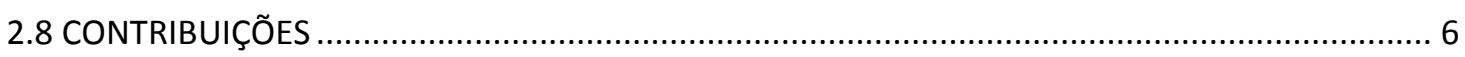

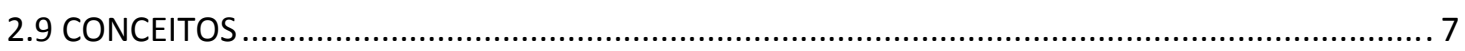

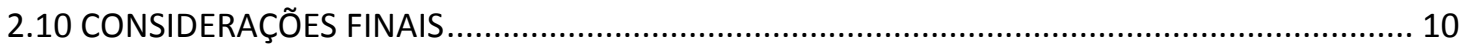

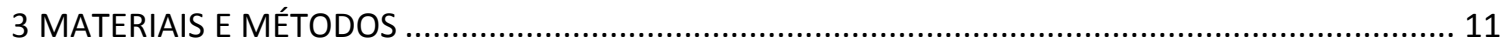

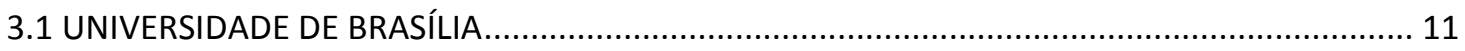

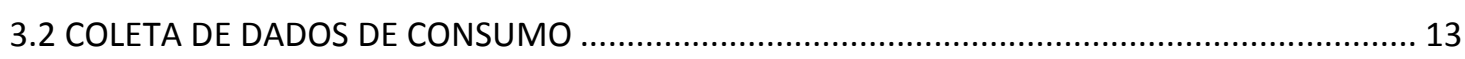

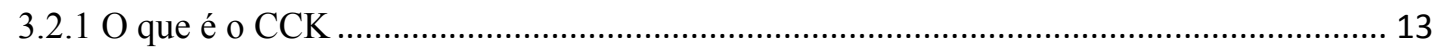

3.2.2 CCK 5100

3.2.3 CCK 4200

3.2.4 CCK 5500

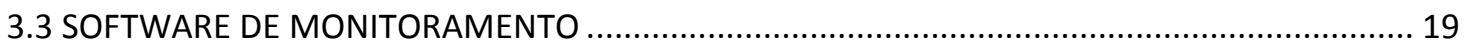




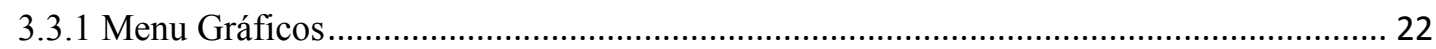

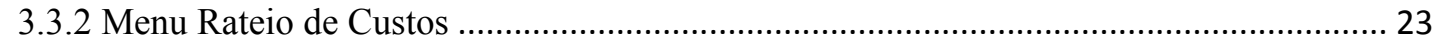

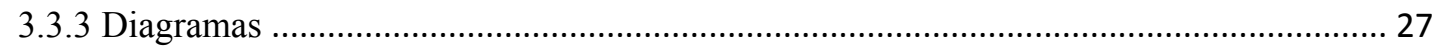

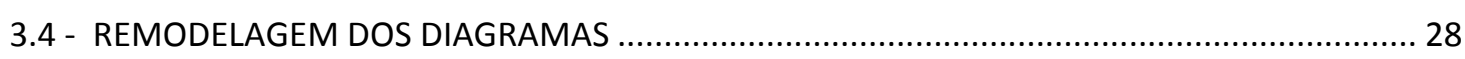

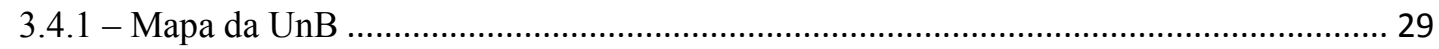

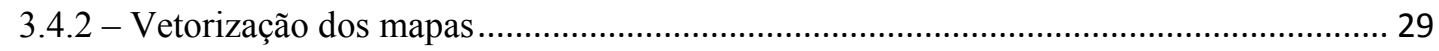

3.4.3- Criação dos novos diagramas..................................................................................... 30

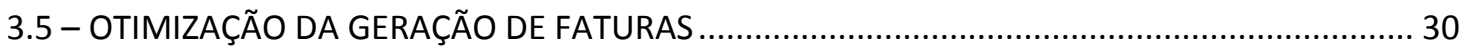

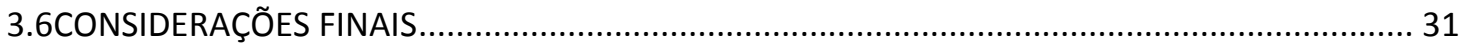

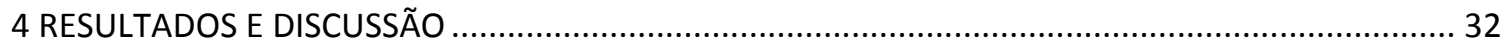

4.1 INSTALAÇÃO DE EQUIPAMENTOS DO SISTEMA DE MONITORAÇÃO ...................................... 32

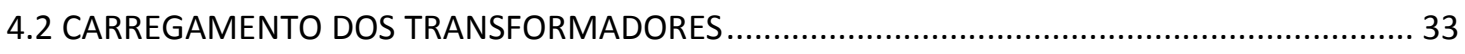

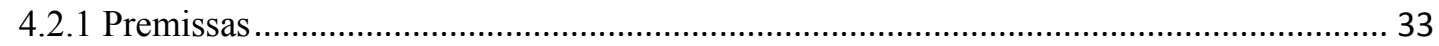

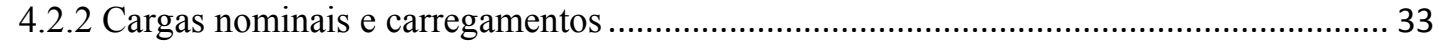

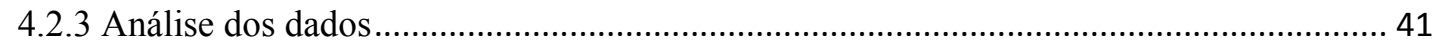

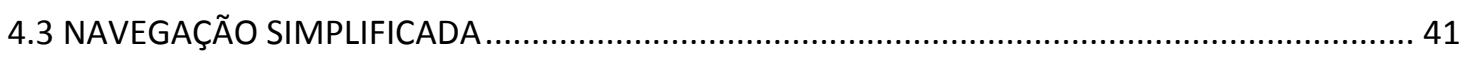

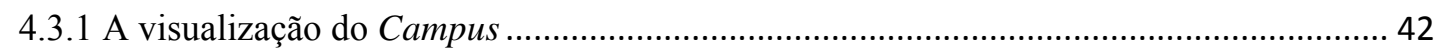

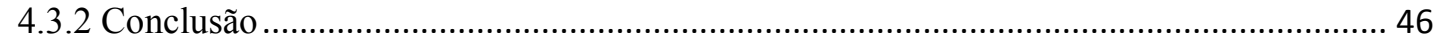

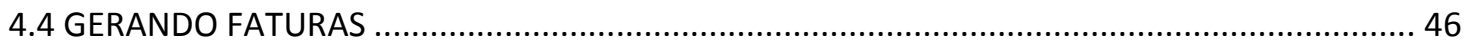

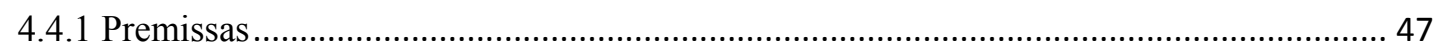

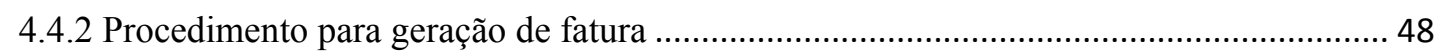

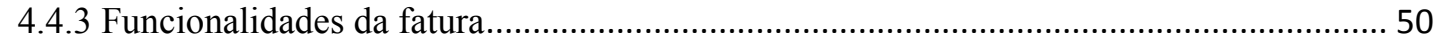

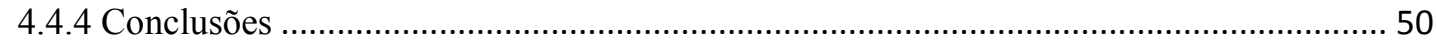

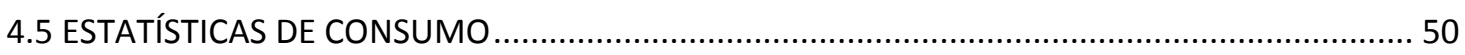

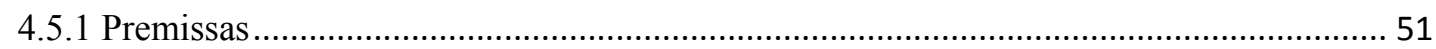




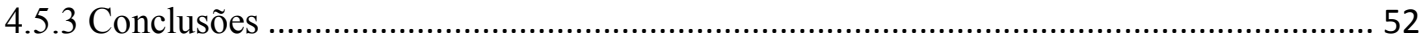

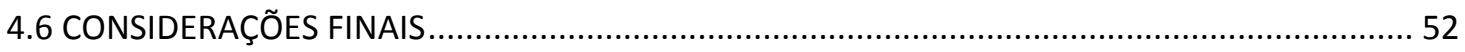

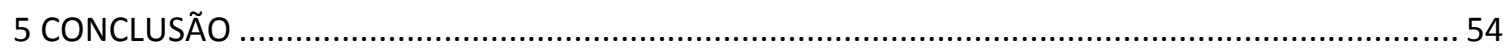

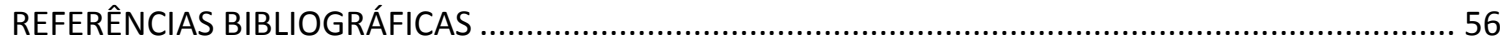

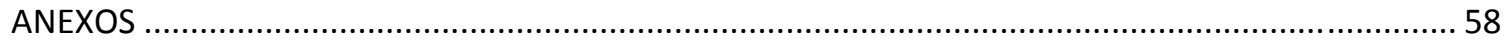

A. FATURA DA CEB RELATIVA AO MÊS DE MARÇO PARA MEDIÇÃO GERAL ..................................59

B. FATURA DO CCK DO MÊS DE MARÇO PARA MEDIÇÃO GERAL .............................................60

C. NOMENCLATURA UTILIZADA PARA A MACRO DE GERAÇÃO DE FATURAS...............................61

D. FATURA GERADA PELA MACRO RELATIVA AO MÊS DE MARÇO DO ALMOXARIFADO...............63 


\section{LISTA DE FIGURAS}

Figura 2.1 - Exemplo de imagem ampliada formada por pixels..................................................... 9

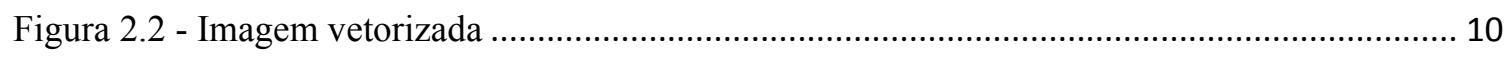

Figura 3.1 - Placa utilizada para o registrador de energia CCK 5100........................................... 14

Figura 3.2 - Esquema de instalação do registrador de energia CCK 5100...................................... 16

Figura 3.3 - Transdutor CCK 4200 instalado na Subestação da Faculdade de Tecnologia............... 17

Figura 3.4 - Esquemática da transferência de dados do CCK 5500 .............................................. 19

Figura 3.5 - Menu principal do software Gerenciador CCK. ..................................................... 21

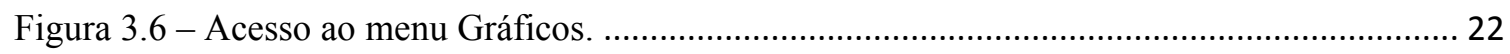

Figura 3.7 - Tela de Gráficos do software Gerenciador CCK, consumo do dia 30/04/2008 do prédio

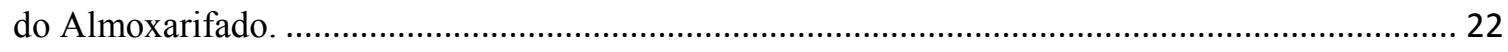

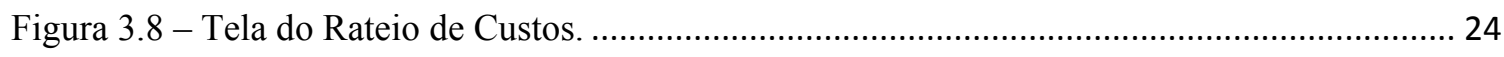

Figura 3.9 - Menu de configuração de tarifas elétricas. .............................................................. 25

Figura 3.10 - Seleção do tipo de rateio a ser feito. …………………............................................ 26

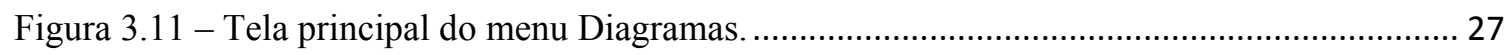

Figura 3.12 - Tela de monitoramento da Faculdade de Tecnologia do menu Diagramas. ............... 28

Figura 3.13 - Mapa aéreo do Campus Darcy Ribeiro................................................................. 29

Figura 4.1 - Visão aérea do Campus Darcy Ribeiro..................................................................... 42

Figura 4.2 - Visão aérea vetorizada do Campus Darcy Ribeiro. .................................................. 43

Figura 4.3 - Aparência antiga da figura referente à Faculdade de Tecnologia................................. 44

Figura 4.4 - Nova tela da Faculdade de Tecnologia no menu Diagramas......................................... 44

Figura 4.5 - Antiga apresentação do diagrama unifilar da Faculdade de Tecnologia......................... 45

Figura 4.6 - Nova apresentação do diagrama unifilar da Faculdade de Tecnologia........................... 46

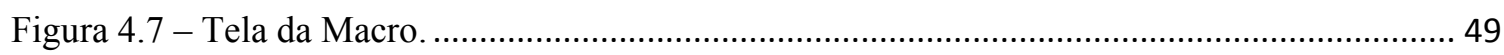




\section{LISTA DE TABELAS}

Tabela 4.1- Locais monitorados pelo sistema CCK e potência nominal de seus transformadores em

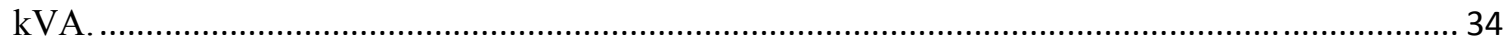

Tabela 4.2 - Análise do carregamento dos transformadores da UnB em Março de 2008. ............... 35

Tabela 4.3 - Consumo por pessoa em Março de 2008 nos prédios SG1, FT, SG11 e SG12............ 52 


\section{LISTA DE SÍMBOLOS E ABREVIATURAS}

A: Corrente em Ampères.

ANEEL: Agência Nacional de Energia Elétrica.

Bitmap: Método de compressão de imagem.

CCK: Empresa que produziu o sistema de monitoramento de energia elétrica utilizado no Campus Darcy Ribeiro.

CDT: Centro de Desenvolvimento Tecnológico.

CEB: Companhia Energética de Brasília.

CEFTRU: Centro de Formação de Recursos Humanos em Transportes.

CEPLAN: Centro de Planejamento Oscar Niemeyer.

CESPE: Centro de Seleção e Promoção de Eventos.

F.U.C.: Fator de Utilização de Carga.

FAC: Faculdade de Comunicação.

FACE: Faculdade de Economia, Administração, Contabilidade e Ciência da Informação e Documentação.

FAU: Faculdade de Arquitetura e Urbanismo.

FAV: Faculdade de Agronomia e Medicina Veterinária.

FD: Faculdade de Direito.

FE: Faculdade de Educação.

FEF: Faculdade de Educação Física.

FS: Faculdade de Ciências da Saúde.

FS: Faculdade de Medicina.

FT: Faculdade de Tecnologia. 
IB: Instituto de Ciências Biológicas.

ICC: Instituto Central de Ciências.

ICS: Instituto de Ciências Sociais.

IdA: Instituto de Artes.

IE: Instituto de Ciências Exatas.

IF: Instituto de Física.

IG: Instituto de Geociências.

IH: Instituto de Ciências Humanas.

IL: Instituto de Letras.

IP: Endereço virtual.

IP: Instituto de Psicologia.

IPOL: Instituto de Ciência Política.

IQ: Instituto de Química.

IREL: Instituto de Relações Internacionais.

Itec: Instituto de Tecnologia em Informática e Informação do Estado de Alagoas.

Jpeg: Método de compressão de imagem.

kVA: Quilovolt-ampère.

kVArh: Energia reativa consumida em um dado período.

kW: Potência Ativa.

kWh: Quilowatt-hora, energia ativa consumida no período de medição.

LED: Diodo Emissor de Luz.

$\mathrm{m}^{2}:$ metros quadrados.

NBR: Norma Brasileira.

PRC: Prefeitura. 
R\$/kWh: Preço em Reais cobrado por quilowatt-hora consumido.

RTU: Unidade terminal remota.

RU: Restaurante Universitário.

SG: Serviços Gerais.

TC: Transformador de Corrente.

TCP/IP: Protocolo de comunicação.

UnB: Universidade de Brasília.

VBA: Linguagem de programação básica.

Vca: Tensão para corrente alternada em Volts. 


\section{RESUMO}

\section{GESTÃO DO CONSUMO DE ENERGIA ELÉTRICA NO CAMPUS DA ASA NORTE DA UNIVERSIDADE DE BRASÍLIA}

O Campus Darcy Ribeiro da Universidade de Brasília, tanto por suas dimensões quanto pela quantidade de atividades realizadas, é um grande consumidor de energia elétrica. Atualmente, por questões ambientais e financeiras, é imprescindível o racionalização desse consumo. Uma forma de alcançar tal objetivo sem comprometer a qualidade de vida e redução de atividades, é aplicar uma gestão inteligente na utilização da energia elétrica.

Para que tal gestão seja bem implementada, faz-se necessário o uso de um sistema que monitore o consumo da energia no Campus. A Universidade já possui uma ferramenta que monitora não só o consumo, mas também grandezas da energia elétrica como corrente, tensão, fator de potência e outros. Esse sistema abrange diversos edifícios da Universidade e faz leitura dos dados dos pontos monitorados a cada 15 minutos.

Com o auxílio desse sistema, do software que faz parte deles e de outros recursos, foi possível criar diversas ferramentas que possibilitam fazer uma gestão inteligente da forma como vem sido utilizada a energia.

Para coleta de dados referentes ao consumo e características da energia recebida nos terminais do Campus e nos prédios, foi utilizado o sistema CCK, que foi o adotado pela Universidade após vários estudos. Utilizou-se também seu software para criar um rateio de fatura por prédio, de forma mais simples e menos trabalhosa.

Por meio do aprimoramento de sua interface gráfica, tornou-se possível a navegação mais simples e intuitiva por todas as edificações monitoradas pelo sistema, permitindo assim que usuários que não estejam familiarizados com esse, rapidamente se adaptem ao seu uso. 
Paralelamente foi possível fazer uma análise de carregamentos dos transformadores das subestações monitoradas, apontando se o equipamento é o correto para as condições a qual está submetido.

Fez-se também possível uma comparação do consumo de energia elétrica em locais que possuem diferentes finalidades de uso, como laboratórios contrastando com salas de aula estritamente teóricas.

De posse de todos esses dados e aprimoramentos feitos ao sistema de monitoração foi possível criar um ambiente mais favorável à gestão do consumo de energia elétrica no Campus e abrir caminhos para contribuições futuras. 


\section{INTRODUÇÃO}

A Universidade de Brasília é uma grande consumidora de energia elétrica, devido às suas atividades e à sua extensão. Sua fatura mensal é de cerca de $\mathrm{R} \$ 400.000,00$. sendo assim, uma redução de poucos por cento de seu consumo pode resultar em uma economia financeira muito alta. Esse resultado pode ser alcançado sem que haja uma redução de suas atividades aplicando uma gestão inteligente ao seu consumo.

Por se tratar da única instituição pública de ensino superior do Distrito Federal e referência nacional, os atos da Universidade acabam sendo notórios para a comunidade como um todo e suas ações podem tornar-se exemplos para a sociedade. Paralelamente a isso, o capital utilizado para o pagamento das faturas é da União, sendo assim, qualquer economia pode ser reaplicada em outros setores.

Conforme vem sendo amplamente divulgada pela mídia, é necessária uma redução no consumo de energia elétrica, mas não é agradável atingir tal objetivo se ocasionar em uma queda da qualidade de vida, com uso de menos aparelhos, redução na iluminação e outros. Sendo assim, aplicando a gestão de energia elétrica na Universidade, pode-se dar exemplo a população a importância desse ato, bem como poupar o meio ambiente.

Esse projeto tem como objetivo aprimorar o sistema de monitoramento de consumo de energia da UnB e, com o auxílio de dados coletados por este, criar diversos dispositivos que permitam evitar desperdícios no Campus, possibilitando a gestão desse consumo. Paralelamente, outros sistemas de diagnósticos acabaram surgindo: análise de carregamento dos transformadores das subestações de unidades monitoradas, comparação estatística de consumo por aluno, funcionário e docente em edificações de diferentes finalidades e um sistema para gerar faturas individuais para cada local monitorado de forma rápida.

O segundo capítulo tem por meta apresentar de forma sucinta a situação do assunto do trabalho atualmente, bem como listar algumas contribuições anteriores e conteúdos abordados. Também são apresentados nele conceitos considerados importantes para que haja melhor compreensão do tema e seu desenvolver. 
A seguir, o terceiro capítulo apresenta os materiais e métodos. Descreve-se sucintamente o Campus Darcy Ribeiro, sua situação atual e os procedimentos seguidos para coleta de dados e desenvolvimento de ferramentas que possibilitem uma gestão inteligente do consumo de energia elétrica.

O capítulo quarto contém os dados coletados e os resultados obtidos a partir destes durante a pesquisa. Primeiramente, apresenta-se a análise dos carregamentos dos transformadores das subestações monitoradas da UnB. Em seguida descreve-se o aprimoramento da interface gráfica do software que acompanha o sistema de monitoramento do Campus Darcy Ribeiro, explicando-se as modificações feitas e seu funcionamento. Por último, é feita uma análise comparativa de edificações com cursos que possuem diferentes características de ensino, tornando possível tirar conclusões quanto ao consumo de acordo com as atividades desenvolvidas.

Finalmente, o capítulo de Conclusão apresenta de forma objetiva o fechamento das análises feitas no trabalho. São feitas também sugestões de como proceder com o tema utilizando as ferramentas já apresentadas, bem como o desenvolvimento de novas.

O documento contém, ainda, uma seção de Anexos, onde se encontram exemplos de conta de luz do Campus, conta gerada pelo sistema de monitoramento, código fonte da atualização do sistema de rateio do sistema, curvas de carga e a nova apresentação de fatura. 


\section{A GESTÃO DA ENERGIA ELÉTRICA}

O capítulo em questão trata da importância da gestão do consumo de energia elétrica, apresentando suas idéias fundamentais e questões específicas do presente trabalho de conclusão de curso. Para que sejam apresentadas de forma clara essas questões, é necessário que se conheça um histórico do consumo de energia elétrica, a necessidade e utilidade de uma gestão inteligente para o Campus da Universidade de Brasília, um trabalho já realizado que auxilia o desenvolvimento do tema e contribuições. Os conceitos e idéias expostos no presente capítulo auxiliam muito a compreensão deste trabalho.

\subsection{ENERGIA ELÉTRICA: EVOLUÇÃO DO CONSUMO}

Iniciado o consumo de energia elétrica para indústrias e fins domésticos, sua oferta era vasta e preços baixos. Um consumo elevado era um fator de status e estimulado. Com o passar dos anos a demanda aumentou de forma considerável, exigindo que se instalassem novas fontes de energia elétrica, várias vezes em locais mais distantes, com um preço e perdas associadas maiores. [OLIVEIRA, 2006]

Chegado o fim do século XX e início do século XXI, não só pelo valor da energia ser bem maior, como por questões físicas e ambientais, sua economia passou a ser estimulada e necessária.

Tornou-se comum a criação de grupos destinados à redução do consumo de energia, bem como cúpulas governamentais envolvendo diversas nações, destinando-se a apresentar soluções inteligentes para um consumo menor de energia.

As conseqüências de um consumo acima do esperado e geração mal planejada puderam ser vistas no Brasil: o "Apagão" em 2001 foi um exemplo claro disso. Foi necessário que todos, desde grandes indústrias até pequenos consumidores, economizassem energia para não deixar o país inteiro às escuras. 


\subsection{EFEITOS DA REDUÇÃO DE CONSUMO DE ENERGIA ELÉTRICA}

Um menor consumo de energia afeta a todos, o consumidor doméstico passa a utilizar menos lâmpadas em sua casa, reduzir a utilização de eletrodomésticos, entre outras medidas que acabam por diminuir a qualidade de vida deste. Na indústria as conseqüências iniciais são mais impactantes: queda na produção e perdas econômicas. Essas perdas podem resultar em uma redução no tamanho das indústrias, gerando desemprego e prejuízos para toda a economia do país. Nesse cenário faz-se necessária a gestão do consumo de energia elétrica.

\subsection{GESTÃO NA UNB}

Tal conceito de gestão deve ser aplicado a instituições de grande porte, como é o caso da Universidade de Brasília, que percorre praticamente toda a Asa Norte, com diversos prédios de diferentes finalidades. Feitos um estudo correto e monitoramento do consumo com avaliação por prédios e faculdades, inventário de equipamentos e controle de sua manutenção, pode-se economizar recursos que podem ser aplicados em compra de equipamentos para laboratório, melhora de estruturas e contratação de novos profissionais.

Essa economia é de grande importância para a sociedade, visto que o capital utilizado na Universidade vem de recursos públicos. Além disso, economia e gestão de energia elétrica em organizações de grande porte contribuem para a preservação do meioambiente, servindo também como um exemplo para a população em geral.

A UnB já teve problemas com consumo elevado de energia, como foi o caso do ano de 2007. Durante o mês de setembro, por problemas técnicos e pelo excesso do uso de aparelhos de ar condicionado, muitos deles antigos e pouco eficientes, ocorreram consumos recordes que chegaram a colocar em perigo o funcionamento dos transformadores da 
subestação do ICC Norte, ultrapassando $100 \%$ de sua capacidade, um valor acima do aceitável para um funcionamento contínuo por vários dias. Houvesse uma monitoração constante com dados bem divulgados, tal comportamento poderia ser previsto e prevenido, evitando o aviso de economia emergencial de energia que foi passado a todos os departamentos.

Com o monitoramento do consumo em tempo real e com uma análise deste, pode-se desenvolver um relatório com índices de desperdício e perdas, auxiliando assim a conscientizar alunos e funcionários a utilizar a energia de forma mais racional. Com essa ferramenta pode-se também convocar auditorias que analisem a situação de forma mais profunda.

\subsection{A FERRAMENTA UTILIZADA}

Vários fabricantes oferecem ferramentas de monitoração que permitem medir diferentes índices como controle de demanda e fator de potência, medição de energia, cargas ativas e reativas entre outros fatores. A UnB já possui um sistema como esse, o CCK, escolhido após estudos feitos pelo Engenheiro João Carlos de Oliveira, em sua dissertação de mestrado.

O CCK faz a medição em tempo real do consumo de energia, fator de potência, cargas ativas e reativas, tensões e correntes e de posse desses dados gera relatórios e análises úteis para o proposto nesse trabalho. Sua estrutura física simplificada favorece seu uso. O sistema consiste em placas ligadas a transdutores que estão diretamente ligados a Transformadores de Corrente conectados à rede elétrica que se deseja monitorar. Essas placas codificam os dados coletados e os enviam por cabos ethernet a computadores que possuam o software fornecido pelo fabricante. Esse software apresenta de forma intuitiva os dados que estão sendo coletados e os armazena para consultas futuras.

Há também diversas medidas que tornam o sistema resistente a falhas, como alarmes que podem alertar sobre falhas em comunicação, índices anormais de tensão, 
corrente e outros fatores que necessitem de maior atenção. A própria placa conectada ao transdutor também possui um banco de dados com todas as informações coletadas nos últimos 15 dias, caso haja uma queda de comunicação que necessite de um tempo grande para ser reparada.

Informações mais precisas sobre o funcionamento do sistema, bem como sua interface e funções principais serão apresentadas em capítulos posteriores.

\subsection{CONTRIBUIÇÕES ANTERIORES}

Houve diversas outras contribuições ao tema de gestão do consumo de energia elétrica na UnB. Entre elas podemos destacar a tese de mestrado do Engenheiro João Carlos de Oliveira Almeida, responsável pela adoção do sistema de monitoramento atual e a tese de mestrado da Engenheira Lilian Silva de Oliveira trata da gestão do consumo de Energia Elétrica no Campus, tomando como foco a apresentação do sistema de monitoramento, as possibilidades de controle que seu uso permite e sua inserção no caso específico da UnB.

\subsection{SITUAÇÃO ATUAL}

Atualmente os dados coletados para o sistema servem somente para monitorar o consumo em tempo real de energia, bem como falhas de comunicação ou falta de energia em locais específicos. Não é feita coleta ou análise de dados por falta de pessoal e metodologia.

\subsection{CONTRIBUIÇÕES}

Esse trabalho tem como objetivo, com o auxílio do sistema de monitoramento atual, fazer um monitoramento inteligente do consumo e da qualidade da energia elétrica do Campus da Universidade de Brasília, sumarizando, organizar sua gestão. Assim é possível economizar energia, gerar estudos estatísticos sobre seu consumo e relatórios que auxiliem seu controle e monitoramento de utilização. 
Para tal, será seguida uma série de estratégias. Uma delas é utilizar os dados coletados pelo sistema adotado, organizá-los e gerar relatórios. Com base nesses relatórios é feito um rateio do consumo bem como o valor da conta cobrada pela CEB para cada faculdade monitorada do Campus da Asa Norte. Os dados são expostos de forma simples e intuitiva possibilitando seu entendimento por qualquer diretor, sem que precise haver conhecimento aprofundado sobre energia elétrica.

O rateio é feito para as faculdades que estão sendo monitoradas, com estimativas de demandas feitas de acordo com a análise de consumo armazenadas nos equipamentos do sistema de monitoração, gerando dessa forma uma espécie de conta de eletricidade, que possibilita um controle mais específico de cada departamento, facilitando até mesmo a solicitação de troca ou a compra de equipamentos.

Outra estratégia é a melhora na interface gráfica do sistema utilizado pela UnB, tornando o sistema mais amigável ao usuário, possibilitando que qualquer pessoa autorizada possa navegar facilmente pelo sistema, conferindo seu consumo, comparando com meses anteriores e, se for do interesse do usuário, verificando dados mais específicos como tensão, cargas ativas e reativas, entre outros. O software do sistema do CCK permite restrição de acesso de usuários, possibilitando que cada um tenha acesso somente aos dados que são destinados a ele.

Também houve o auxílio na instalação e troca de diversos equipamentos do sistema de monitoramento utilizado pela Universidade.

Uma explanação mais completa de todas essas contribuições será apresentada nos capítulos seguintes.

\subsection{CONCEITOS}

O conhecimento de alguns conceitos se faz necessária para a compreensão adequada do presente trabalho:

- TARIFA: A ANEEL, Agência Nacional de Energia Elétrica, define tarifa como:

"Preço da unidade de energia elétrica e/ou da demanda de potência ativas." 
"Os consumidores de energia elétrica pagam por meio da conta recebida da sua empresa distribuidora de energia elétrica, um valor correspondente a quantidade de energia elétrica consumida, no mês anterior, estabelecida em $\mathrm{kWh}$ (quilowatt-hora) multiplicada por um valor unitário, denominado tarifa, medida em $\mathrm{R} \$ / \mathrm{kWh}$ (reais por quilowatt-hora), que corresponde.

As empresas de energia elétrica prestam este serviço por delegação da União na sua área de concessão, ou seja, na área em que lhe foi dado autorização para prestar o serviço público de distribuição de energia elétrica.

Cabe à Agência Nacional de Energia Elétrica - ANEEL estabelecer tarifas que assegurem ao consumidor o pagamento de uma tarifa justa, como também garantir o equilíbrio econômico-financeiro da concessionária de distribuição para que ela possa oferecer um serviço com a qualidade, confiabilidade e continuidade necessárias."

As tarifas podem ser mudadas de acordo com os padrões de consumo do contratante caso a concessionária considere coerente.

- Outros conceitos importantes como demanda, fator de potência e fatura possuem sua descrição de forma muito precisa na RESOLUÇÃO DA ANEEL N ${ }^{\circ} 456$ DE NOVEMBRO DE 2000. A inserção dessa variedade de conceitos adicionaria um volume desnecessário a este capítulo.

- Gestão: Uma boa definição para gestão foi encontrada no site da Itec, Instituto de Tecnologia em Informática e Informação do Estado de Alagoas:

“A gestão de energia elétrica articula, promove, apóia e desenvolve ações visando à maior eficiência no uso e na conservação dos recursos energéticos pela Administração Pública, mediante atuação específica, no planejamento e na execução institucional, financeira, tecnológica, gerencial e promocional.

A gestão também estabelece princípios, metas, normas e padrões para o uso eficiente e racional da energia elétrica pelo Estado, acompanha, avalia e divulga os resultados obtidos, além de promover e realizar estudos e incentivar a criação de programas de racionalização e conservação de energia específica por tipo e uso final. 
$\mathrm{Na}$ redução dos gastos com energia elétrica, essa política adota medidas negociais, técnicas e educativas.";

- Vetorização: Para uma melhor compreensão da melhora da interface gráfica do software do CCK, é necessária a definição de vetorização.

Arquivos de imagem em formatos como Bitmap, Jpeg e outros são compostos por pixels, que são pontos individuais coloridos dispostos de maneiras diferentes de modo a formar uma imagem. Ao ampliarmos imagens formadas por pixels, cada vez mais estes se tornam evidentes, resultando em algo desfigurado, como a figura abaixo:

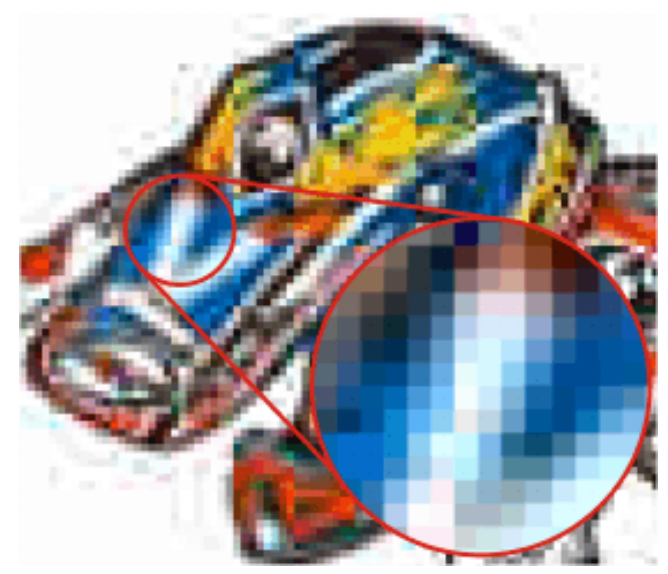

Fonte:Vetorizar. Disponível em <www.vetorizar.com/vetorizar/definicao.htm> Acesso em: 06 de Junho de 2008.

Figura 2.1 - Exemplo de imagem ampliada formada por pixels.

A visualização mais evidente de pixels, como a apresentada acima é chamada comumente de "pixelização". Uma forma de evitar esse problema é transformar o arquivo de imagem em um arquivo vetorial. Vetores são entidades matemáticas compostas de um módulo e ângulo com relação a um referencial específico. Cada vetor em um arquivo desses é uma identidade com propriedades próprias, como cor, forma, contorno e posição na tela já incluídos em sua definição. Como vetores são entidades independentes, é possível ampliar e reduzir uma imagem sem que haja perdas em sua nitidez ou resolução, além de evitar dificuldades em sua visualização. [AJS, 1999]. 


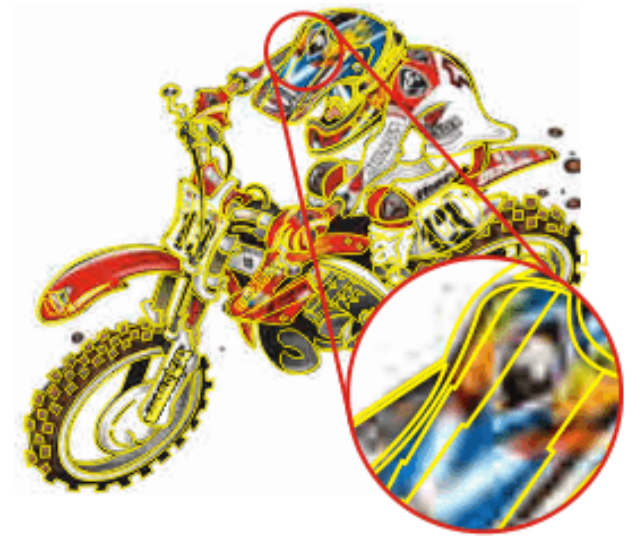

Fonte:Vetorizar. Disponível em <www.vetorizar.com/vetorizar/definicao.htm> Acesso em: 06 de Junho de 2008.

Figura 2.2 - Imagem vetorizada

\subsection{CONSIDERACÕES FINAIS}

Esse capítulo apresentou um cenário atual do objeto de pesquisa do trabalho que o contém, informando conceitos necessários para a compreensão do tema bem como outras informações importantes, facilitando assim o desenvolvimento do conteúdo. 


\section{MATERIAIS E MÉTODOS}

No capítulo são apresentados os materiais e métodos utilizados na obtenção das informações referentes ao consumo de energia elétrica no Campus do plano piloto. Tais informações vão subsidiar o entendimento do processo de geração de contas e utilização da interface de monitoramento em tempo real, sendo estas medidas que visam à melhor gestão do consumo da energia.

\subsection{UNIVERSIDADE DE BRASÍLIA}

A Universidade de Brasília foi fundada em 21 de abril de 1962, apenas dois anos após a inauguração da cidade, inicialmente com apenas 413 alunos. O espaço ocupado por esse Campus, na época o único da UnB, já era previsto no projeto original da cidade, feito pelo urbanista Lúcio Costa e pelo Arquiteto Oscar Niemeyer. Sua área se extende por praticamente toda Asa Norte e é limitada pelas vias L3 Norte e o pelo Lago Paranoá. Naquela época sua área construída era de aproximadamente $13 \mathrm{mil} \mathrm{m}$, 35 vezes menor que em 2006. Já em 2005, o Campus alcançava 30.118 alunos regulares, sendo esses de graduação, especialização, mestrado e doutorado [UnB, 2008].

Atualmente, com 46 anos, o Campus Darcy Ribeiro possui cerca de 10 faculdades e 12 institutos:

-Faculdade de Agronomia e Medicina Veterinária (FAV)

-Faculdade de Arquitetura e Urbanismo (FAU)

-Faculdade de Ciências da Saúde (FS)

-Faculdade de Comunicação (FAC)

-Faculdade de Direito (FD) 
-Faculdade de Economia, Administração, Contabilidade e Ciência da Informação e Documentação (FACE)

-Faculdade de Educação (FE)

-Faculdade de Educação Física (FEF)

-Faculdade de Medicina (FS)

-Faculdade de Tecnologia (FT)

-Instituto de Artes (IdA)

-Instituto de Ciência Política (IPOL)

-Instituto de Ciências Biológicas (IB)

-Instituto de Ciências Exatas (IE)

-Instituto de Ciências Humanas (IH)

-Instituto de Ciências Sociais (ICS)

-Instituto de Física (IF)

-Instituto de Geociências (IG)

-Instituto de Letras (IL)

-Instituto de Psicologia (IP)

-Instituto de Química (IQ)

-Instituto de Relações Internacionais (IREL)

Hoje em dia, por suas dimensões elevadas e intenso uso de equipamentos elétricos em seus departamentos e faculdades, se faz necessária a monitoração do consumo de energia elétrica.

Desse modo, atualmente há a monitoração de energia na maioria dos prédios do Campus, sendo os prédios monitorados: 
Almoxarifado, Observatório Sismológico, ICC Sul, ICC Norte, Reitoria, Biblioteca Central do Estudante, Faculdade de Tecnologia, Faculdade de Educação 01, 03 e 05, sendo que as duas últimas possuem uma única leitura, Faculdades de Medicina e Saúde, CEPLAN, CEFTRU, Centro Comunitário, Garagem e oficina, Núcleo de Medicina Tropical, Pavilhão Anísio Teixeira, Pavilhão João Calmon, Multiuso I e II, FA, Restaurante Universitário, SG 01, SG 09, SG 11, SG 12, Prefeitura, o novo prédio do Instituto de Química, o prédio do CESPE, Geocronologia, e, futuramente, o prédio em construção do novo Instituto de Biologia e o CDT.

\subsection{COLETA DE DADOS DE CONSUMO}

A tarefa de monitorar e gerir o consumo de energia elétrica no Campus faz com que seja necessário coletar e analisar, constantemente, informações como: tensão, corrente, potência, fator de potência e outros dados relacionados ao fornecimento de energia elétrica. A coleta e análise destes dados são auxiliadas pelo de sistema de monitoramento, da empresa CCK, e é descrito de forma mais detalhada na tese de mestrado da Engenheira Lilian Silva de Oliveira.

\subsubsection{O que é o CCK}

Este sistema de monitoramento supracitado tem como objetivo servir de ferramenta de auxílio para a atividade de gestão do consumo de energia elétrica. É composto por vários dispositivos de hardware, responsáveis pela captura e envio dos dados à unidade central, como um microcomputador, e ainda por software de análise dos dados que é compatível com os sistemas operacionais Windows 95/98/NT/XP.

A instalação do CCK vai desde a linha a ser monitorada até o computador onde são observados os dados coletados. Atualmente, além do software instalado na unidade central do Campus, existem outros três equipamentos instalados em vários pontos da rede elétrica da UnB, sendo eles: CCK 5100, CCK 4200 e CCK 5500. A seguir é apresentada uma descrição de cada um deles. 


\subsubsection{CCK 5100}

O CCK 5100 é um gerenciador de energia que faz a monitoração de energia junto à medição da concessionária, com funções de controle de demanda, fator de potência e programação horária, podendo monitorar até 60 cargas simultaneamente.

Sua comunicação é feita através de uma porta de programação no padrão ETHERNET, com protocolo de comunicação TCP/IP, permitindo programação, leitura e registro de dados na memória e uma comunicação em tempo real a uma velocidade limite de $10 \mathrm{Mbps}$.

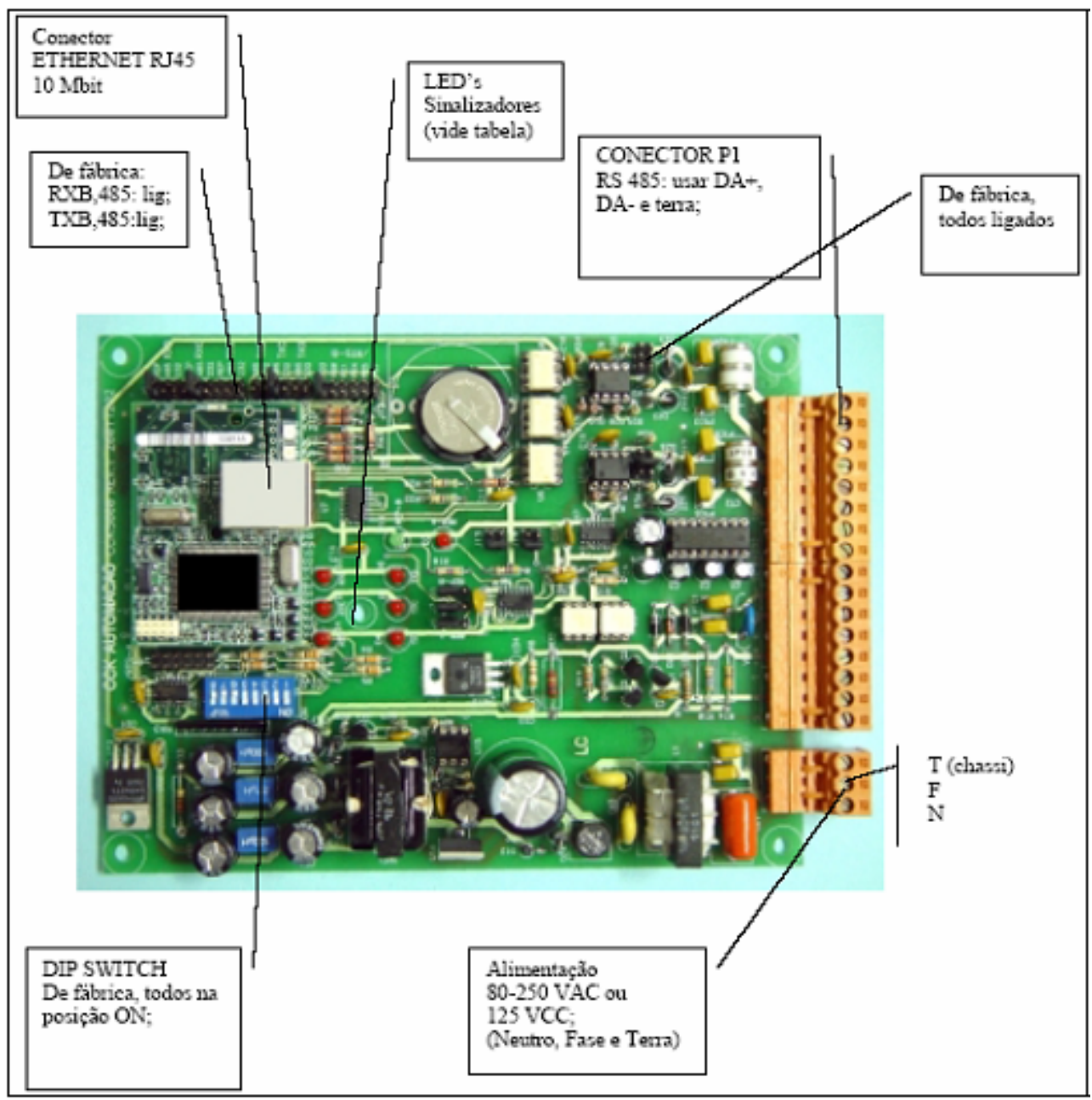

Figura 3.1 - Placa utilizada para o registrador de energia CCK 5100. 
Os dados são pré-armazenados em memória do próprio dispositivo e são tranferidos, de forma automática e periódica por meio de porta de comunicação ETHERNET, utilizando o protocolo TCP/IP. Os dados são então enviados e armazenados em um banco de dados localizado em um computador no qual o software tenha sido instalado e configurado previamente. O banco de dados em questão é capaz de armazenar registros de vários dias e seu limite está condicionado à capacidade de armazenamento e processamento do microcomputador em uso.

Entre os dados coletados estão os registros de índices de qualidade exigidos pela ANEEL: DIC - duração em minutos de todas as interrupções de energia, FIC - número de interrupções de energia e DMIC - duração da maior interrupção de energia.

O dispositivo também possui uma porta de comunicação serial RS 485, protocolo de comunicação MODBUS RTU, por onde são disponibilizados parâmetros para supervisão, que incluem dados do equipamento como: estado (ligado/desligado), consumo de energia entre outros. Há outra porta desse tipo para comunicação com módulos de acionamento para controle de demanda, fator de potência e programação horária. Estas funcionalidades podem ser encontradas no CCK 512 mas, como não fazem parte do sistema instalado na UnB, seu funcionamento não é explicado.

Cada dispositivo CCK 5100 possui uma memória mantida por bateria, permitindo o armazenamento dos dados por cerca de 10 dias mesmo sem estar alimentado pela rede elétrica convencional.

Um esquema da instalação desse equipamento pode ser visto a seguir. 


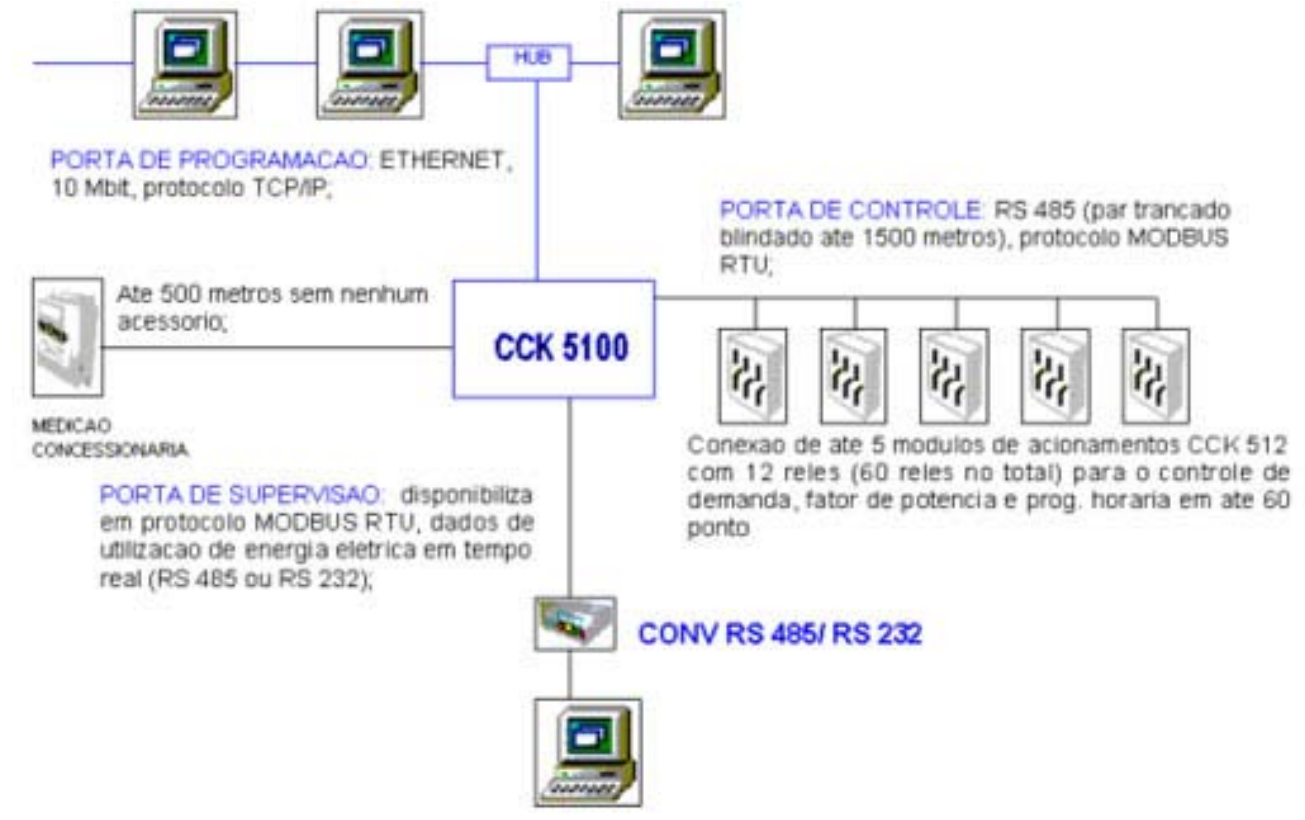

Figura 3.2 - Esquema de instalação do registrador de energia CCK 5100.

Atualmente existem dois equipamentos CCK 5100 instalados no Campus da UnB, os quais são os responsáveis pela Medição Geral e RU Caldeiras.

\subsubsection{CCK 4200}

O CCK 4200 é um transdutor de energia. Transdutores podem receber e enviar sinais analógicos. Nesse caso, o aparelho converte em sinais digitais os dados analógicos recebidos do TC e calculados: potências ativa, reativa e aparente, consumo em $\mathrm{kW}$ kWh e VArh, fator de potência médio e por fase, tensão média e por fase, corrente média e por fase e freqüência, todos com um erro associado máximo de $0,5 \%$. Após a conversão em sinais digitais, esses parâmetros são armazenados por um registrador de dados que será descrito no tópico seguinte. 


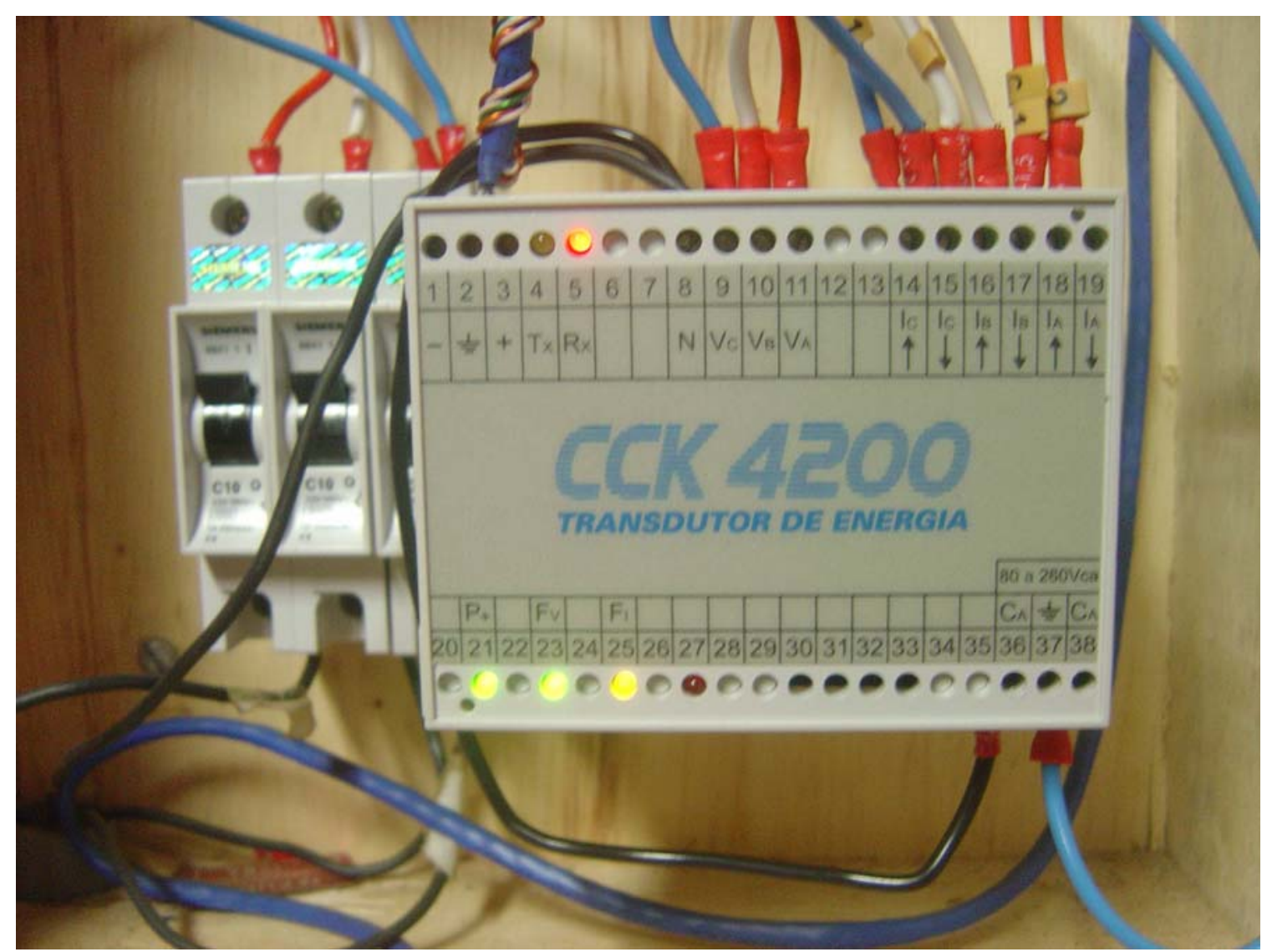

Figura 3.3 - Transdutor CCK 4200 instalado na Subestação da Faculdade de Tecnologia.

Além disto, este dispositivo suporta conexão direta com TCs acoplados em linhas com tensões de até 500Vca e corrente de 5A. Possui ainda oito chaves externas de seleção do tipo dip switch as quais permitem selecionar o tipo de ligação para medição, seleção do endereço RTU e velocidade de conexão.

Assim como o CCK5100, possui uma saída serial RS485 e LEDs que auxiliam a instalação correta: o faseamento de sinais de corrente e a atividade de comunicação (transmissão e recepção).

Atualmente existem 40 CCK 4200 instalados no Campus da Asa Norte da Universidade de Brasília. 


\subsubsection{CCK 5500}

Concentradores de dados são equipamentos existentes como soluções de determinados fabricantes que recebem os dados de vários medidores ou transdutores. Os concentradores se comunicam com o sistema de monitoração, enviando-lhe os dados armazenados quando solicitados pelo sistema. Os registradores são concentradores de dados recebendo os dados dos medidores em forma de pulso serial [ALMEIDA, 2003]

Com o mesmo hardware semelhante do CCK 5100, Figura 3.1, porém com uma programação diferente, o CCK 5500 é um registrador de dados responsável por coletar os dados do transdutor CCK 4200 e repassá-los ao sistema. Possui uma memória para registros de até 15 dias, sendo que a memória do primeiro dia é substituída com a chegada do $16^{\circ}$ dia e assim sucessivamente.

O CCK 5500 recebe os dados do transdutor CCK 4200 divididos em 18 campos, sendo que os dados armazenados em cada campo são uma média integrada dos últimos 15 minutos das leituras realizadas. É a chamada memória de massa.

Este é a último equipamento do sistema CCK presente antes da ligação com os microcomputadores onde estão instalados os softwares do sistema. Sua conexão é feita através de um HUB, utilizando-se cabos do tipo UTP, os mesmos utilizados em redes domésticas, com conectores do tipo RJ45 nas extremidades. Sua velocidade de conexão é de até $10 \mathrm{Mbps}$. Recebe dados de até 7 transdutores CCK 4200 e, antes da transmissão para as máquinas que possuem o programa cedido pela empresa, armazenam os dados em uma memória de massa.

Para a programação, assim como o CCK 5100, possui chaves que acionadas na ordem correta permitem a definição de um IP específico para que se possa fazer a discriminação do equipamento e edificação de onde estão sendo coletados os dados. Atualmente existem 27 CCK 5500 instalados no Campus Darcy Ribeiro. A seguir, um esquema de funcionamento da transferência de dados da placa em questão. 


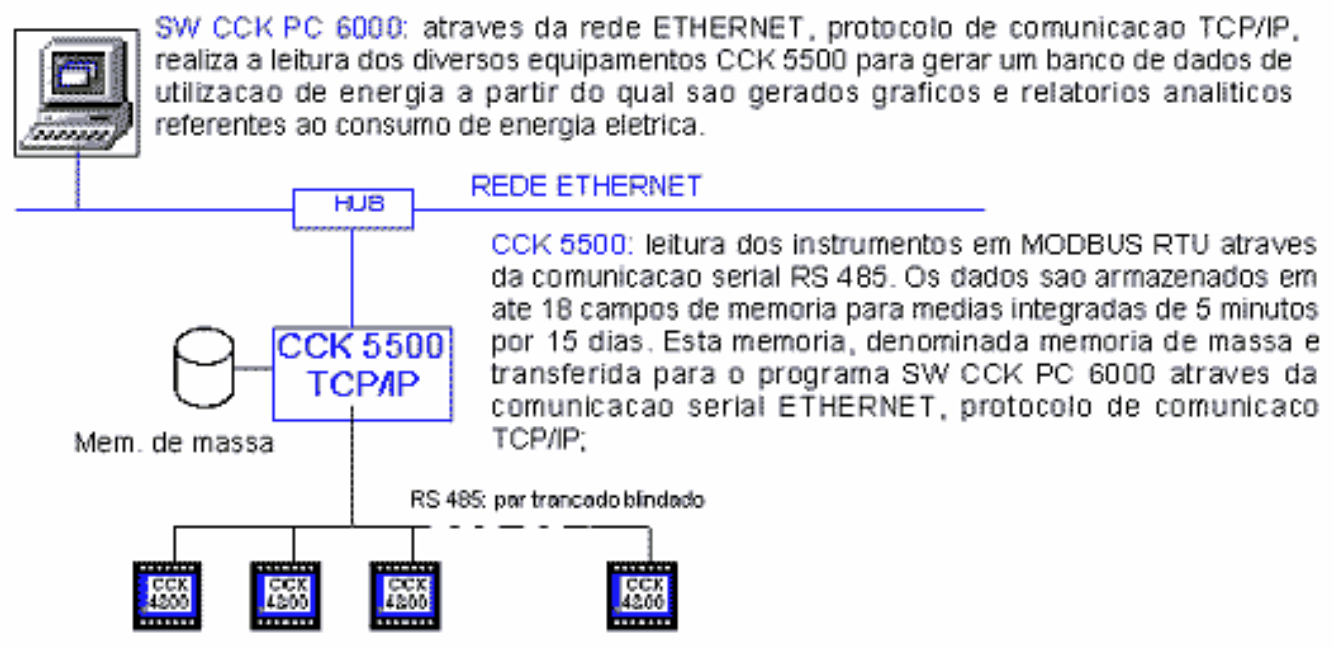

Figura 3.4 - Esquemática da transferência de dados do CCK 5500.

\subsection{SOFTWARE DE MONITORAMENTO}

$\mathrm{Na}$ aquisição dos equipamentos de hardware que compõem o sistema de monitoramento, a empresa CCK fornece também, software de gestão. Este software, o Gerenciador CCK, é responsável pela coleta, armazenamento e processamento dos dados adquiridos pelos dispositivos CCK 4200, CCK 5500 e CCK 5100.

Trata-se, na verdade, de um conjunto de vários softwares integrados por um gerenciador comum, responsável por organizar os dados coletados e apresentá-los de uma forma que possa auxiliar o monitoramento do sistema instalado. A cada 15 minutos cada unidade monitorada entra se comunica com o sistema por meio do protocolo TCP/IP e registra as informações adquiridas desde a última comunicação.

O software em questão possui diversas funções, como gráficos do consumo mensal, consumo de cada dia, com escolha da escala desejada sendo de 15 minutos a menor disponível e ainda, podem ser configurados alarmes para sinalização de queda de energia, comunicação ou mau funcionamento. Neste trabalho, as funções que foram mais utilizadas foram: o rateio de consumo com geração de conta de acordo com a tarifa e a inspeção de parâmetros como potência, tensão, corrente e fator de potência em tempo real dos locais monitorados. 
O programa permite modificações do próprio usuário. Sua distribuição e atualizações são gratuitas, bem como algumas alterações que possam vir a serem solicitadas. Porém, caso tais alterações sejam consideradas muito profundas, esse serviço é cobrado.

Atualmente o software está instalado em quatro máquinas no Campus, a unidade central no Laboratório de Qualidade de Energia no SG 11, que seria o computador chefe, em um computador na sala do Chefe do Departamento de Energia Elétrica, cargo atualmente ocupado pelo Professor Marco Aurélio Gonçalves de Oliveira e em dois computadores da administração da prefeitura, que seriam os computadores usuários, que podem somente acessar leitura do sistema. Somente a unidade central tem acesso a programação e funções mais específicas. O software pode ser instalado em qualquer computador e adquirir informações em tempo real do sistema instalado na UnB. A navegação do usuário pelo sistema pode ser controlada por meio de senha, limitando a disponibilidade das funções para um determinado perfil.

A barra de botões azul situada acima da figura esquematizada do mapa do Campus Darcy Ribeiro, situada na Figura 3.5, é interativa e possui as seguintes funções:

- Gerenciamento: Permite entrar nas funções: Gráficos, onde é possível ver em tempo real o consumo registrados pelos CCK 5500 e CCK 5100 instalados:

-Relatórios, onde é possível gerar relatórios de consumo, demanda e outros;

- Rateio de Custos, onde, a partir de tarifas definidas pelo próprio usuário, épossível gerar uma conta de luz.

-Gráficos e Rateio de Custos serão explicadas mais minuciosamente a adiante;

- Leitura de Memória: Permite proceder com a leitura dos dados atualmente armazenados nos equipamentos CCK 5100 e CCK 5500. Essa leitura está definida como automática, não sendo necessário acioná-la em condições normais;

- Supervisão: Permite acessar os submenus: 
-Comunicação, onde é exibido o status da comunicação entre o sistema e os vários dispositivos CCK;

-Supervisão, onde é possível iniciar e suspender a comunicação com equipamentos CCK;

-Alarmes, que podem ser ajustados para alertar sobre falhas de comunicação, queda de luz, ultrapassagem de demanda e outros problemas relevantes; Eventos, que lista as anormalidades ocorridas na comunicação e Diagramas, que será explicado de forma mais completa ainda nesse Capítulo;

- Programação: Onde se programam as placas CCK com dados como endereço de IP, grandezas a serem computadas, entre outros;

- Configuração: permite a criação de perfis de usuários e senhas além da configuração dos locais de armazenamento dos backups dos dados entre outras funcionalidades;

- Ajuda: Possui alguns tutoriais simples sobre localização e funções do programa, apresentados de forma bem sucinta.

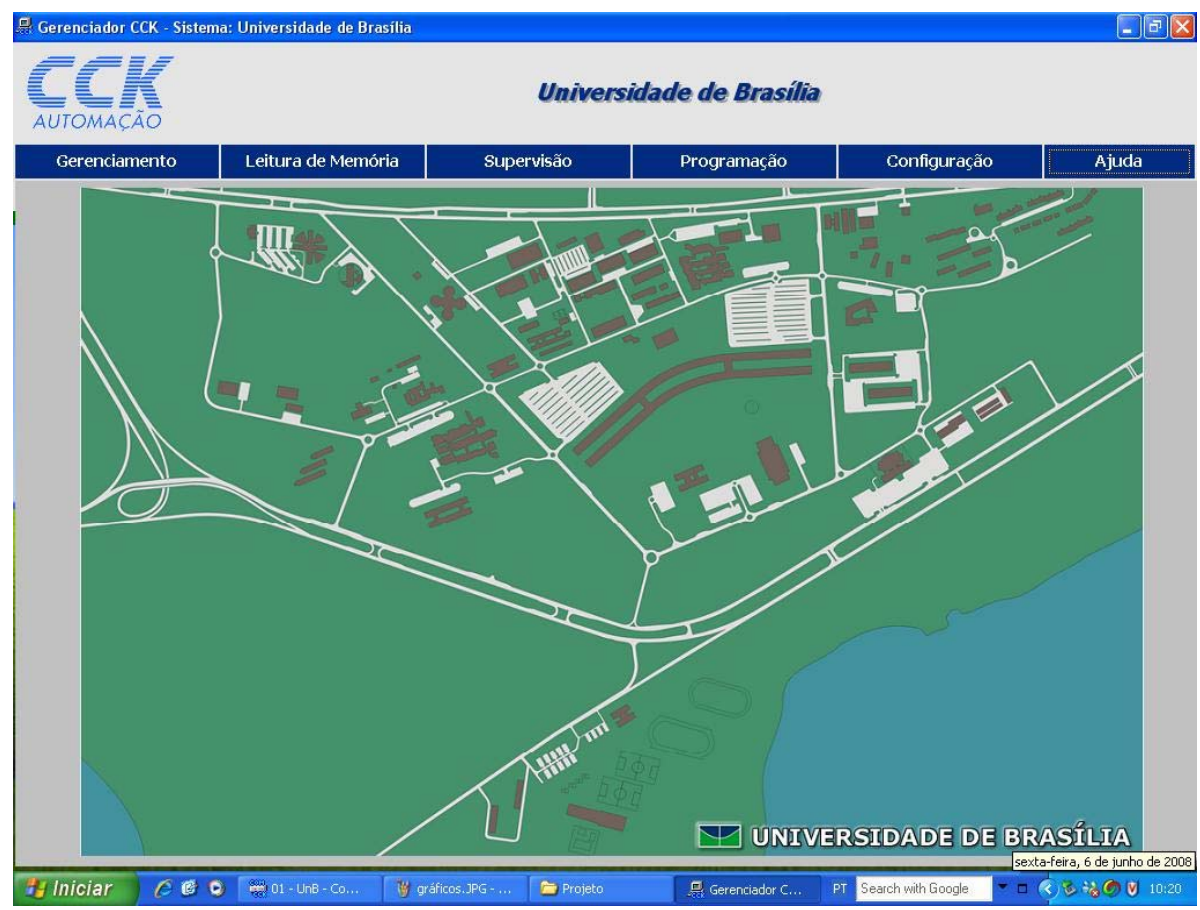

Figura 3.5 - Menu principal do software Gerenciador CCK. 


\subsubsection{Menu Gráficos}

Conforme dito anteriormente, no menu Gerenciamento é possível acessar o menu

\section{Gráficos:}

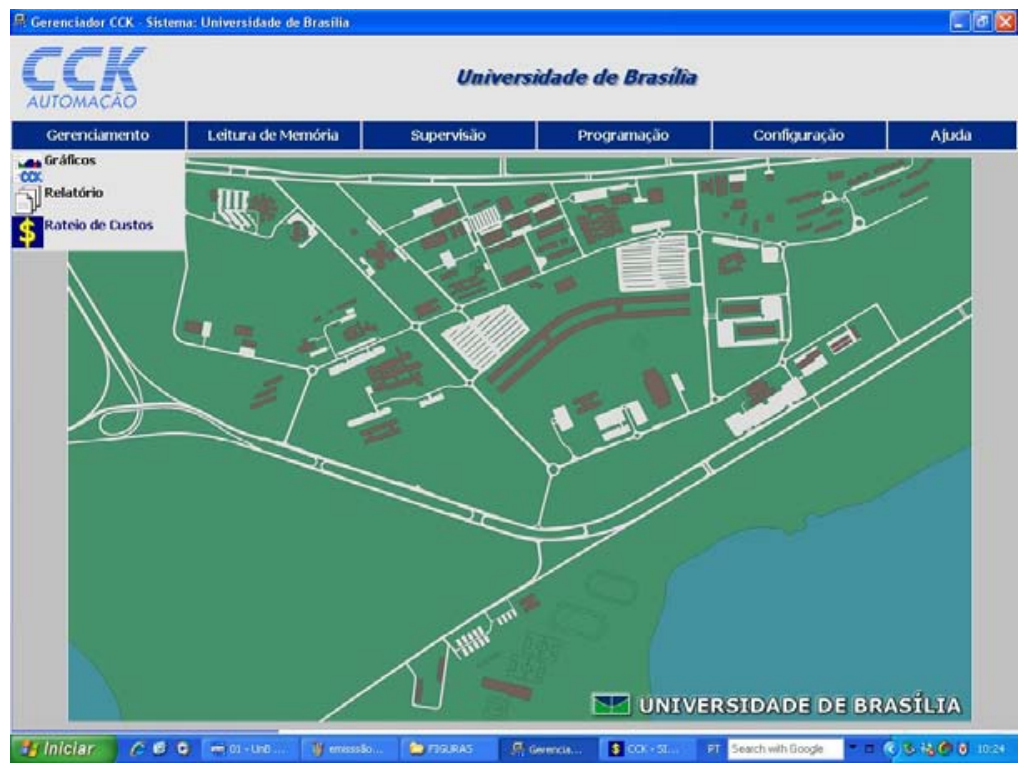

Figura 3.6 - Acesso ao menu Gráficos.

Ao clicar no menu Gráficos, a seguinte tela é apresentada ao usuário:

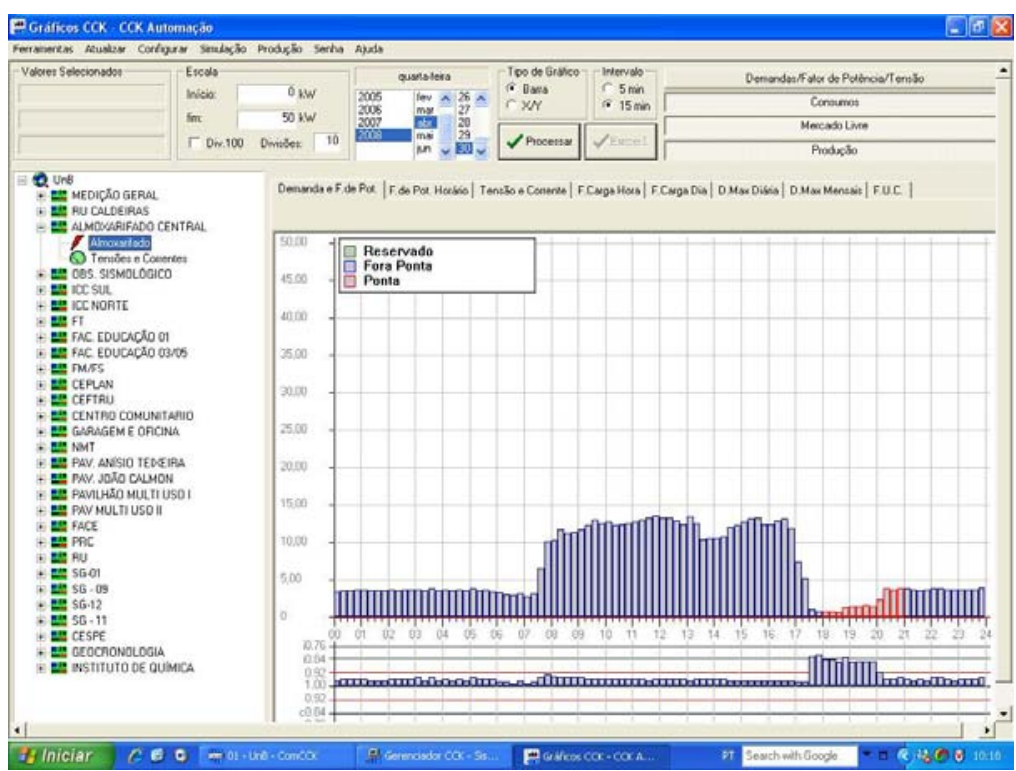

Figura 3.7 - Tela de Gráficos do software Gerenciador CCK, consumo do dia 30/04/2008 do prédio do Almoxarifado. 
Como é possível verificar, por meio dessa tela é possível selecionar as edificações, listadas na parte esquerda, cujas características deseja-se observar. Pode-se determinar a escala do gráfico e a data específica a ser visualizada. O botão "Processar" permite salvar alterações feitas na escala. Acima do gráfico, é possível perceber um menu com diversas opções de grandezas medidas. No caso da Figura 3.7, estão representadas a demanda e o fator de potência, bem como os horários de ponta, em vermelho, e fora de ponta, em azul.

Pode-se observar também o fator de potência horário, tensão, corrente, fator de carga por hora, fator de carga por dia, a demanda máxima em um dia específico e durante o mês e o fator de utilização de carga (F.U.C.). As outras funções disponíveis nesta tela não são muito utilizadas e, portanto, não serão explicadas neste trabalho.

Além da escolha da edificação, é possível também optar pela visualização de um transformador específico monitorado pelo sistema. Esta funcionalidade é bastante útil quando existem mais de uma dispositivo instalado no local, como é o caso do ICC Norte, permitindo assim, a observação de cada um dos transformadores que alimentam o prédio separadamente.

\subsubsection{Menu Rateio de Custos}

Ao selecionarmos a opção Rateio de Custos na tela principal (Figura 3.5), é apresentada a seguinte tela (Figura 3.8): 


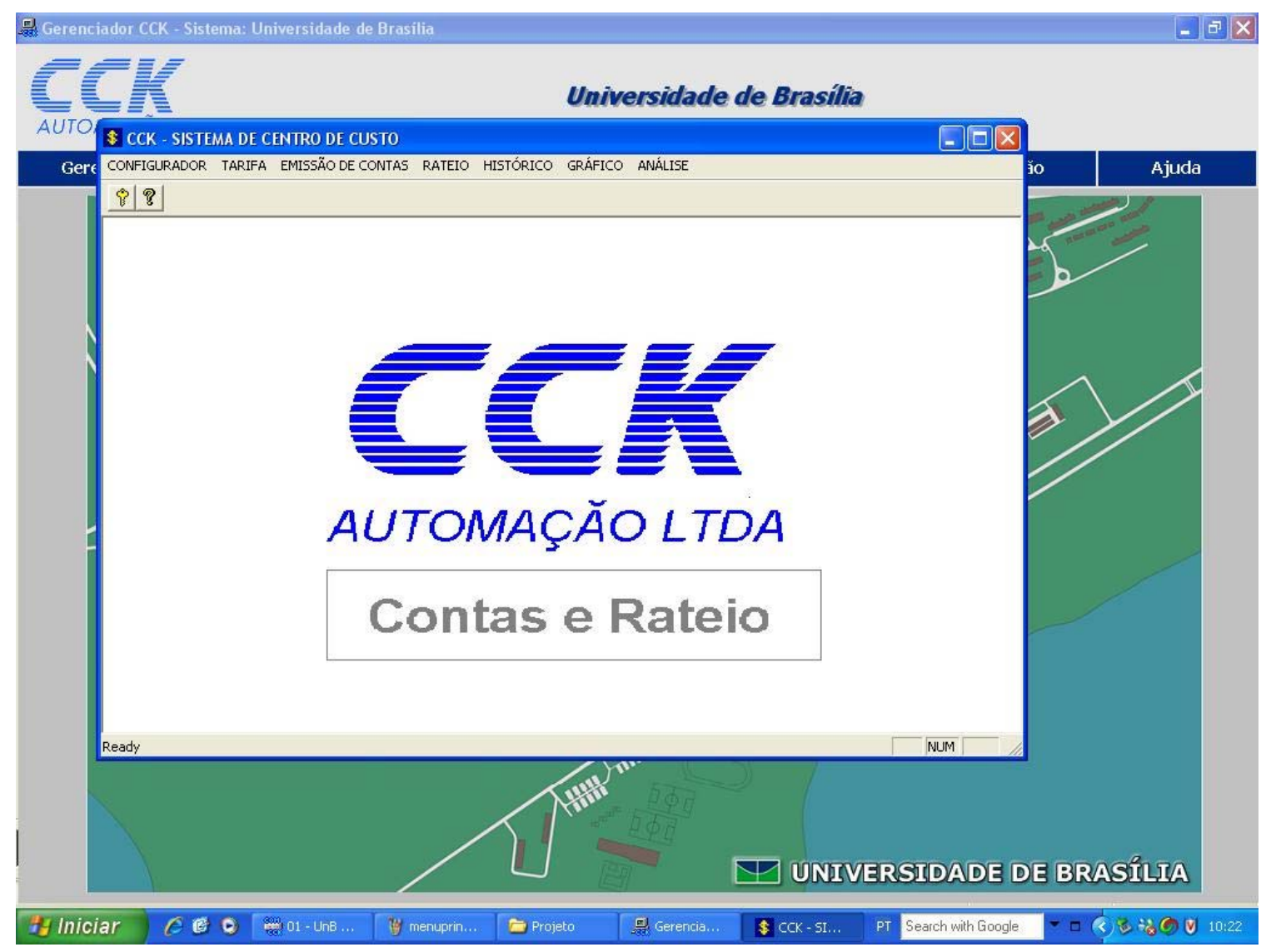

Figura 3.8 - Tela do Rateio de Custos.

As funções nela contidas que são de relevância para esse trabalho são:

- Configurador: Nessa função, é possível configurar quais unidades constituem um Centro de Custo, uma Medição Global e Tipo de Custo. Para Centro de Custo, foram definidos os prédios, como FT, FS entre outros. Para a Medição Global, definiu-se RU caldeiras e Medição Geral, que são as duas unidades onde estão instalados os CCK 5100 e também as duas unidades para as quais a CEB emite faturas para a administração da UnB. O Tipo de Custo é meramente para controle, definindo se o prédio em questão trata-se de uma unidade administrativa, com sala de aulas, com laboratórios, de forma a permitir observação de algum padrão de consumo para diferentes tipos de uso do local.

- Tarifa: Nessa função, utilizamos somente a parte de Tarifas Elétricas, a seguir. 


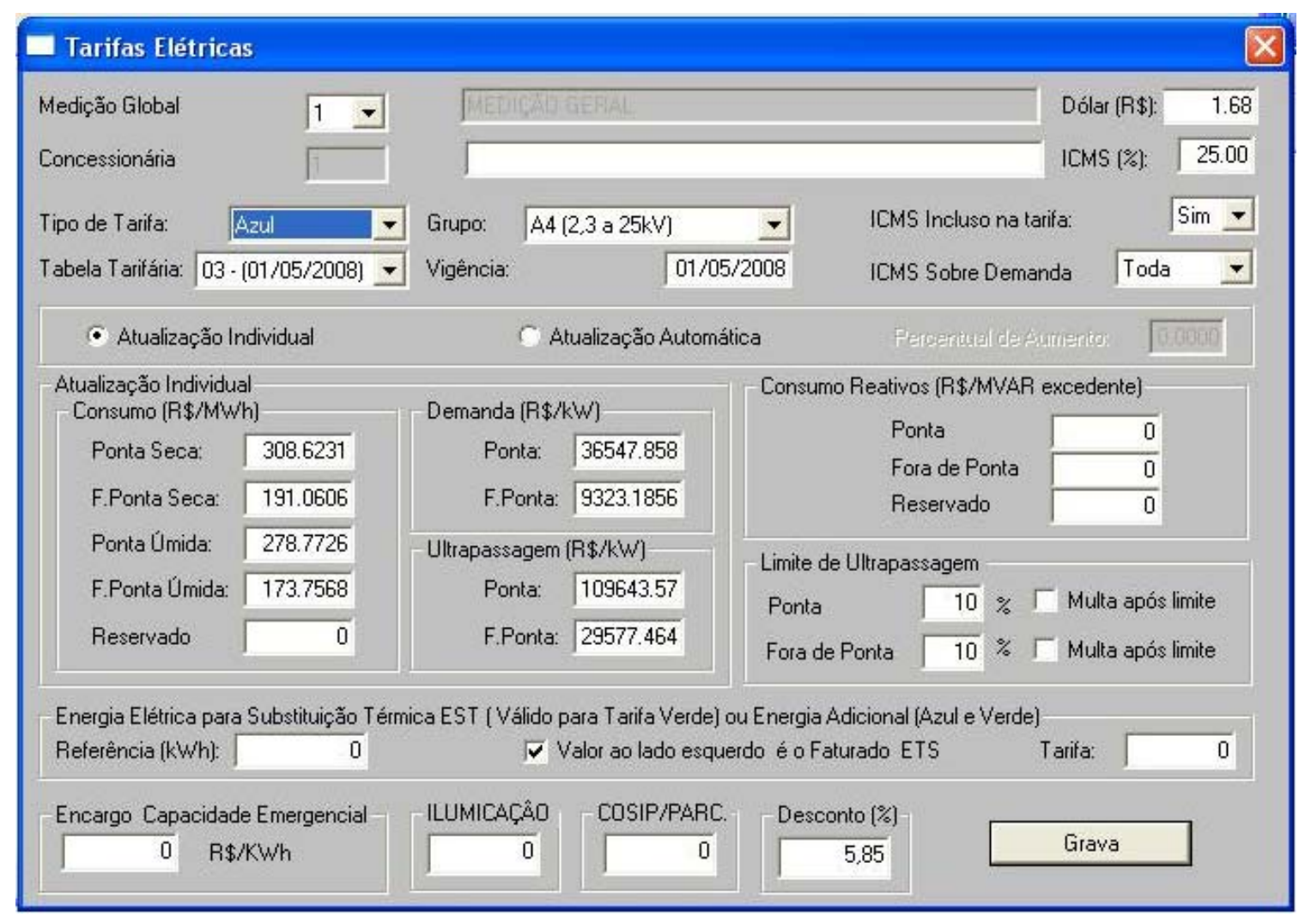

Figura 3.9- Menu de configuração de tarifas elétricas.

Nesse menu, foram definidos valores adquiridos no site da CEB para os custos. A tarifa contratada é a Tarifa Horo-Sazonal Azul, conforme pode ser visto em "Tipo de tarifa". Em "Tabela Tarifária”, escolhe-se a tarifa de acordo com a data na qual começa a vigorar. No caso, a Figura 3.9 mostra tarifa que entrou em vigor apartir de maio de 2008. No mesmo campo, é possível observar tabelas de tarifas configuradas anteriormente para fins de comparação ou mesmo reutilização. Como pode ser visto na Figura 3.9, é possível configurar todos as tarifas de Consumo, Demanda e Ultrapassagem, em R $\$ / M W h, R \$ / k W$ e $\mathrm{R} \$ / \mathrm{kWh}$, respectivamente. Pode-se também definir custo devido à iluminação pública, algumas tarifas e desconto. Os valores estipulados para esses parâmetros serão explicados no Capítulo 4.

- Emissão de Contas: Talvez uma das mais relevantes funções do programa para o trabalho em questão. Esse menu permite fazer um rateio do consumo, gerando uma espécie 
de fatura por unidade monitorada, de acordo com a tarifa e data definidas. A tela onde se seleciona o tipo de rateio está apresentado na Figura 3.10:

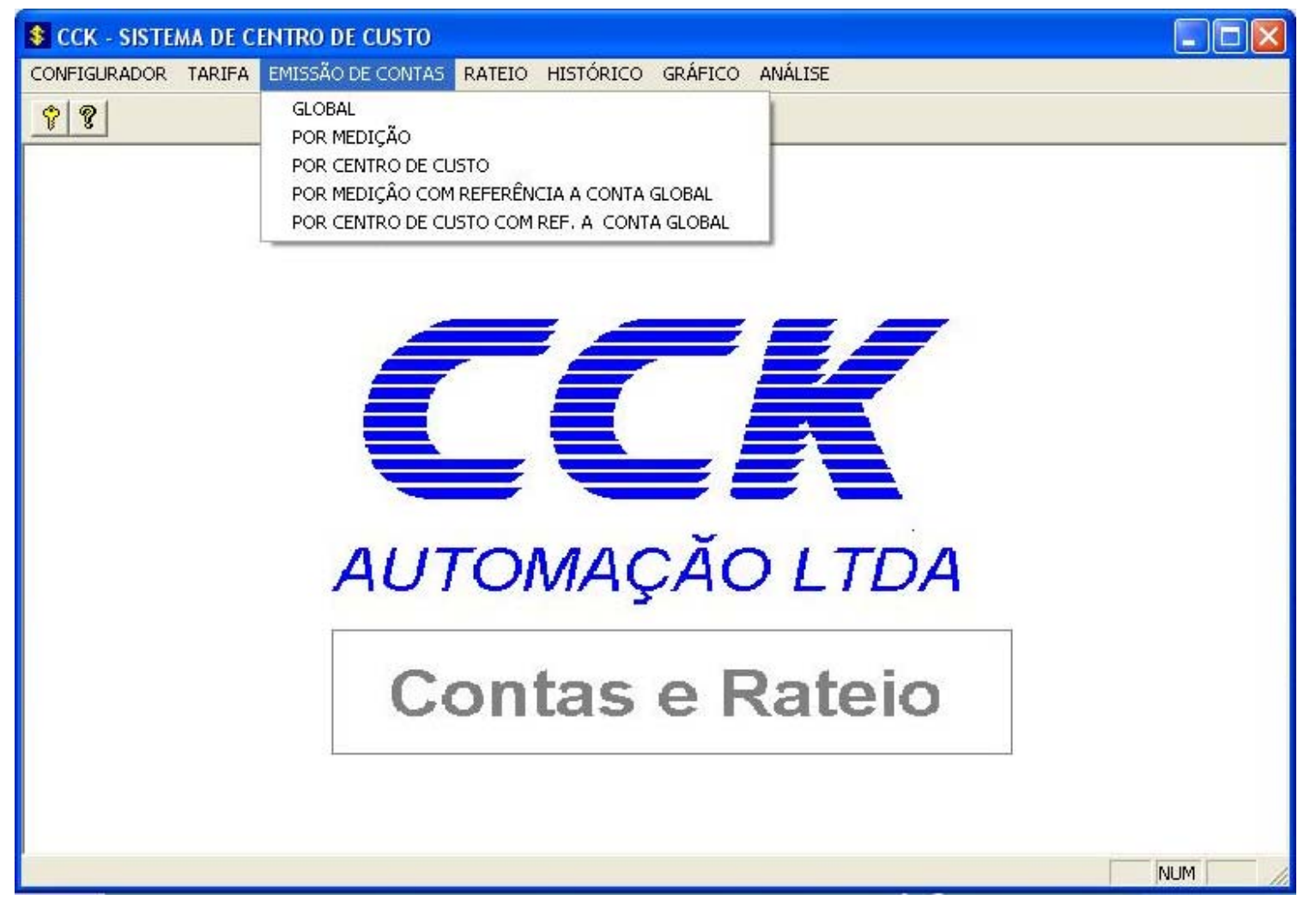

Figura 3.10 - Seleção do tipo de rateio a ser feito.

A opção GLOBAL permite a geração de conta para os equipamentos CCK 5100, relativos à Medição geral e ao RU Caldeiras. A opção POR MEDIÇÃO permite emitir uma fatura para cada transformador ou linha monitorada e a opção POR CENTRO DE CUSTO permite a emissão de fatura por edificação, considerando inclusive a soma de todas as linhas e transformadores monitorados que fazem parte de um certo ponto alimentação. As outras opções não foram utilizadas para a realização desse trabalho. 


\subsubsection{Diagramas}

Esse menu permite a navegação pelo Campus de forma mais intuitiva e amigável ao usuário. Permite visualizar em tempo real diversas grandezas do local monitorado, como tensão, corrente, fator de potência e outros.

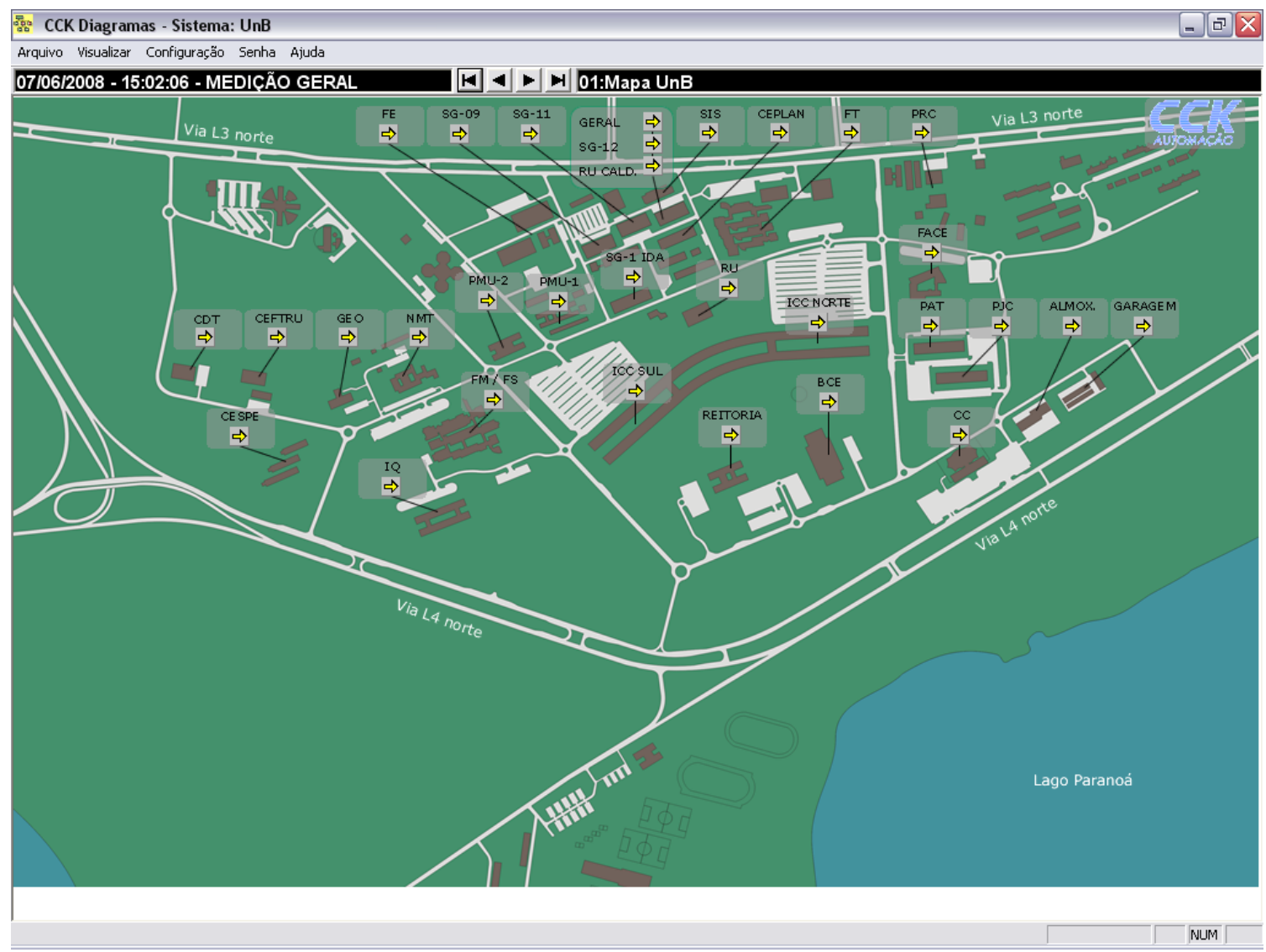

Figura 3.11 - Tela principal do menu Diagramas.

Nesse menu configuram-se a figura que será mostrada por prédio e a função de cada botão presente nela. Na Figura 3.11 acima, que é uma versão esquematizada da vista aérea do Campus da UnB, estão mostrados todos os prédios monitorados pelo sistema CCK, dando dois "cliques" em uma das setas amarelas, o usuário é direcionado para a tela específica da unidade em questão. 


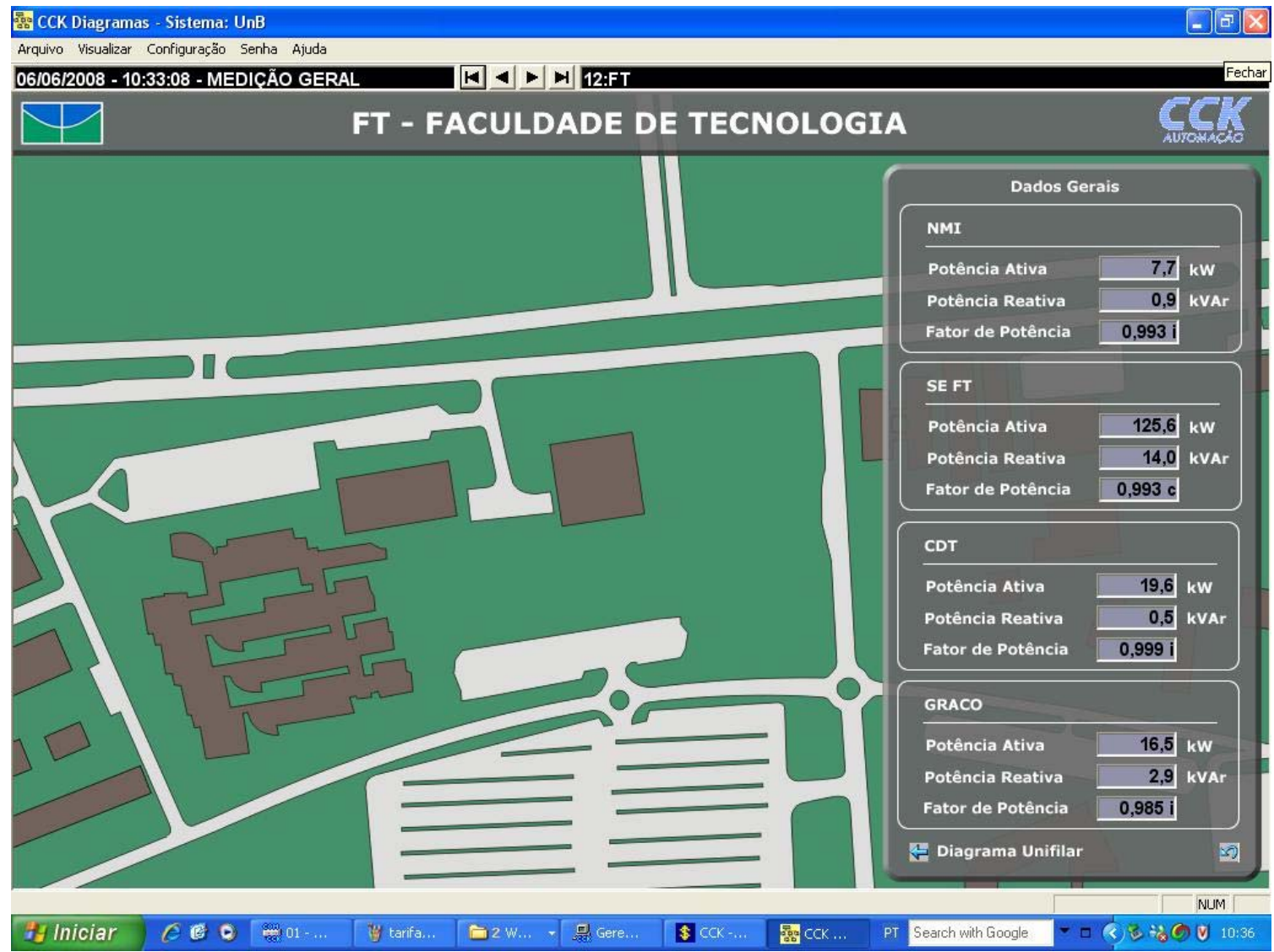

Figura 3.12 - Tela de monitoramento da Faculdade de Tecnologia do menu Diagramas.

Na Figura 3.12 acima, está um exemplo da tela que o usuário vê ao selecionar o prédio da Faculdade de Tecnologia. Cada moldura branca refere-se a uma fonte de alimentação do prédio. No rateio, são somados os consumos dos quatro. Na base do quadro cinza à direita da figura, há os botões que possibilitam visualizar o diagrama unifilar do sistema de monitoração do prédio e outro logo a sua direita que permite retornar ao diagrama principal da Figura 3.11.

\section{4 - REMODELAGEM DOS DIAGRAMAS}

O processo de criação dos novos modelos de diagramas exigiu o uso de alguns poderosos softwares de tratamento de imagens. 


\subsection{1 - Mapa da UnB}

A etapa inicial consistia em obter um mapa atual da UnB e com resolução razoável para posteriormente executar a vetorização das imagens. Sendo assim, primeiramente foram utilizadas imagens via satélite do Google Earth, obtidas em vários quadrantes, os quais foram consolidados possibilitando a obtenção de um mapa aéreo bem detalhado do Campus Darcy Ribeiro. O mapa obtido pode ser visualizado na Figura 3.13 abaixo.

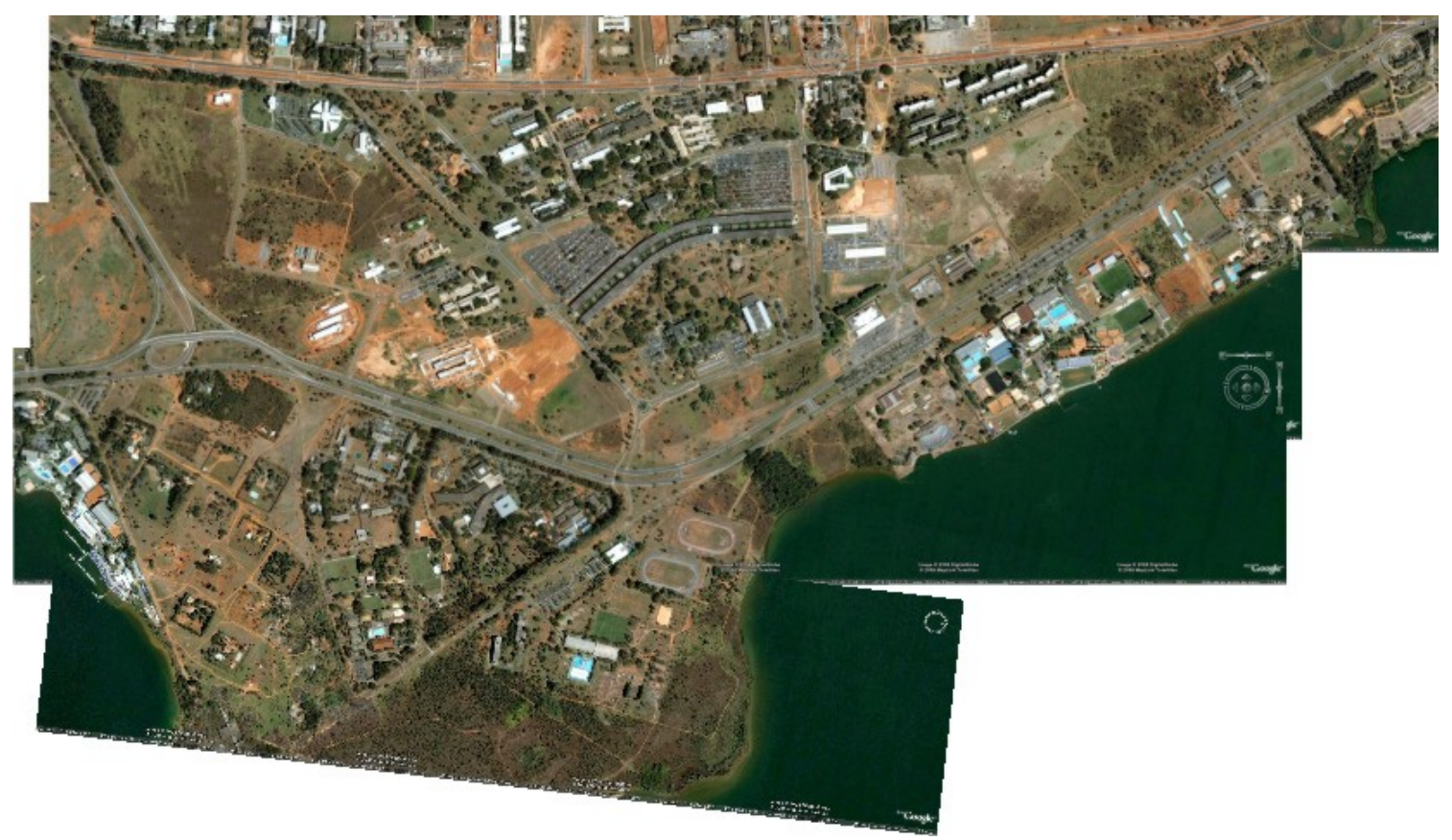

Figura 3.13 - Mapa aéreo do Campus Darcy Ribeiro.

\subsection{2 - Vetorização dos mapas}

Nesta etapa, o procedimento consiste em redesenhar os principais objetos presentes no mapa tais como, edificações, avenidas e área verde, transformando-as em formas vetoriais para o desenvolvimento de imagens mais apropriadas às atividades desenvolvidas.

Sendo assim, o mapa original foi trabalhado, com um software de edição de imagens, permitindo a obtenção de um mapa vetorial e simplificado do Campus Darcy 
Ribeiro. O mapa vetorial obtido terá cópia salva em computador do Laboratório de Qualidade de Energia permitindo futuras alterações.

Porém, o software sistema CCK que exibe os diagramas reconhece apenas imagens na extensão Bitmap e, sendo assim, as imagens vetoriais não podem ser utilizadas diretamente naquele sistema.

Por conseguinte, o mapa gerado foi exportado com resolução suficiente e em formato JPEG para próximas etapas de criação dos diagramas.

\subsection{3- Criação dos novos diagramas}

Para a criação dos digramas, os quais necessitam de campos específicos para adequação ao software do CCK, foi utilizado um programa com o qual foram criados cada um dos diagramas necessários e suas respectivas cópias para alterações futuras.

Finalmente foram gerados os arquivos finais em formato Bitmap os quais foram atualizados no sistema CCK. Com os novos diagramas configurados foi possível então criar uma interface mais simples e de fácil navegação pelo sistema.

\section{5 - OTIMIZAÇÃO DA GERAÇÃO DE FATURAS}

Embora o sistema CCK possua software capaz de gerar faturas, a disposição dos dados, as informações geradas e disposição no texto deixam a desejar. Uma vez que faz parte do objetivo deste trabalho obter ferramenta eficiente de gestão, incluindo a geração de faturas de fácil leitura, foi necessária a criação de programa em linguagem VBA (Visual Basic for Applications).

VBA é uma linguagem de programação simples que acompanha produtos Microsoft Office. A programação em VBA permite executar tarefas como gerar planilhas, textos e banco de dados de maneira automática sendo especialmente útil quando se trata da execução de tarefas repetitivas [MUELLER, 2007]. 
Usando esta linguagem de programação, foi criado então um arquivo EXCEL o qual permite a geração de faturas de energia elétrica no formato desejado.

O programa criado no arquivo EXCEL, o qual tem a função de capturar as faturas geradas pelo sistema CCK, também em formato EXCEL, permite a emissão de faturas de acordo com as necessidades da Universidade de Brasília.

Para a criação do programa em VBA, ou Macro, foi levado em consideração que o processo de geração manual das faturas pelo sistema CCK segue certo padrão. Determinado o padrão do procedimento, a Macro foi criada considerando ainda que a pessoa responsável pela geração das faturas não possua conhecimentos em programação. Desta forma, existe uma interface gráfica que permite ao usuário selecionar quais faturas deseja gerar. Explicações mais precisas sobre a interface e seu funcionamento são dadas no capítulo 4.

$\mathrm{O}$ arquivo de EXCEL, o qual carrega a Macro programada internamente, fica armazenado no mesmo computador onde está instalado o sistema CCK. O programa não possui qualquer tipo de bloqueio e pode ser editado a qualquer momento.

\subsection{CONSIDERAÇÕES FINAIS}

Esse capítulo apresenta sucintamente a Universidade de Brasília, materiais e métodos utilizados para gerar ferramentas que possibilitem uma gestão eficiente de energia elétrica no Campus Darcy Ribeiro. É mostrado também o sistema de monitoramento de consumo de energia elétrica utilizado atualmente na Universidade. De posse desses dados, o leitor torna-se ciente da instrumentação utilizada para a análise presente no capítulo 4. 


\section{RESULTADOS E DISCUSSÃO}

Esse capítulo aborda os resultados mais relevantes obtidos com as contribuições feitas com relação à monitoração do consumo e características da energia elétrica do Campus Asa Norte da Universidade de Brasília e uso dos dados coletados. Apresenta-se também uma discussão sobre esses resultados, propondo soluções para problemas ocasionalmente encontrados.

\subsection{INSTALAÇÃO DE EQUIPAMENTOS DO SISTEMA DE MONITORAÇÃO}

Ao longo do projeto, auxiliamos a instalação de dispositivos da rede CCK em algumas edificações. Os locais visitados, datas e serviço realizado foram registrados.

Houve uma visita em 01/02/2008 ao prédio CEFTRU, onde houve a necessidade da troca de três Transformadores de Corrente de 250/5A por três Transformadores de Corrente de 400/5A, permitindo assim que fossem monitorados os dois prédios do CEFTRU. Na situação anterior, os três TCs estavam conectados a um disjuntor responsável pelo prédio antigo apenas, deixando o prédio novo não monitorado. Poderiam ser instalados também três TCs de 250/5 A no disjuntor responsável pelo prédio novo, mas por escassez de espaço no quadro, foi necessária a instalação descrita acima na montante do disjuntor geral que alimenta os dois disjuntores, monitorando assim ambos os prédios.

Em 28/09/2007 auxiliou-se a instalação de uma placa CCK5500 e duas CCK4200 no novo prédio do CESPE, utilizando-se seis TCs de 1000/5 A já disponíveis no local, possibilitando a monitoração deste prédio.

Em 09/10/2007 foi feita a instalação de uma placa CCK5500 e uma CCK4200 no prédio novo do Instituto de Química, utilizando três TCs de 1600/5 A já disponíveis no local, possibilitando assim que o prédio se tornasse o primeiro com consumo monitorado desde sua inauguração.

Finalmente em 29/01/2008 instalou-se uma placa CCK5500 e uma CCK4200 no prédio da Geocronologia utilizando-se três TCs de 400/5 A, já disponíveis no local. 


\subsection{CARREGAMENTO DOS TRANSFORMADORES}

Um levantamento importante que pode ser feito graças ao CCK é a carga que a maioria dos transformadores do Campus Asa Norte da Universidade de Brasília alimentam. De posse desses dados junto à potência nominal de cada transformador, obtidos junto à Prefeitura do Campus, foi possível fazer a análise que se segue.

\subsubsection{Premissas}

Uma forma de calcular se o carregamento de um transformador está adequado de forma a assegurar uma vida útil longa é seguir as orientações da NBR 5416/81, revisada em 1997. Infelizmente para seguir essa recomendação, é necessária uma coleta precisa de dados sobre a temperatura do óleo do transformador, bem como temperatura dos enrolamentos. Outro empecilho encontrado foi a realidade da UnB: os transformadores devem possuir a maior vida útil possível e nem sempre recebem o cuidado e a manutenção ideal, além de alguns deles já estarem em operação por um longo período (cerca de 30 anos). Para contornar essas situações, partiu-se da premissa de que o carregamento adequado para os transformadores tem limite de $80 \%$ de sua carga nominal em operação normal e $130 \%$ de sua carga nominal em situações de emergência de curta duração (máximo de 3 horas).

\subsubsection{Cargas nominais e carregamentos}

Junto à Prefeitura do Campus, obteve-se a tabela a seguir, que contém o local monitorado pelo sistema CCK e a potência nominal de cada transformador que alimenta o local. As unidades que possuem mais de um transformador têm sua potência nominal descrita da seguinte forma: (Quantidade de transformadores)x(Potência nominal de cada equipamento). 
Tabela 4.1- Locais monitorados pelo sistema CCK e potência nominal de seus transformadores em $\mathrm{kVA}$.

\begin{tabular}{|c|c|}
\hline LOCAL MONITORADO & POTÊNCIA NOMINAL EM kVA \\
\hline Almoxarifado Central & 15 \\
\hline Observatório Sismológico & 150 \\
\hline ICC Sul e Reitoria & $3 \times 500$ \\
\hline ICC Norte e BCE & $3 \times 500$ \\
\hline Faculdade de Educação 01 & 112,5 \\
\hline Faculdade de Tecnologia & $3 \times 150$ e 500 \\
\hline Faculdade de Educação 03/05 & 112,5 \\
\hline Faculdade de Medicina/Faculdade de Saúde & $2 \times 500$ \\
\hline CEPLAN & 150 \\
\hline CEFTRU & 225 \\
\hline Centro Comunitário & 150 \\
\hline Garagem e Oficina & 75 \\
\hline Núcleo de Medicina Tropical & 75 \\
\hline Pavilhão Anísio Teixeira & 112,5 \\
\hline Pavilhão João Calmon & 112,5 \\
\hline Multiuso I & 150 \\
\hline Multiuso II & 75 \\
\hline FACE & $2 \times 112,5$ \\
\hline Prefeitura & 150 \\
\hline Restaurante Universitário & 500 \\
\hline
\end{tabular}




\begin{tabular}{|c|c|}
\hline SG-01 & 150 \\
\hline SG-09 & 150 \\
\hline SG-12 & 225 \\
\hline SG-11 & 150 \\
\hline Geocronologia & 225 \\
\hline Instituto de Química & $2 \times 500$ \\
\hline CESPE & $2 \times 500$ \\
\hline
\end{tabular}

Feita uma análise para o mês de março de 2008, chegou-se à conclusão quanto a cada prédio, descrita na tabela 4.2:

Tabela 4.2 - Análise do carregamento dos transformadores da UnB em Março de 2008.

\begin{tabular}{|c|c|}
\hline LOCAL MONITORADO & ANÁLISE DO MÊS DE MARÇO DE 2008 \\
\hline Almoxarifado Central & $\begin{array}{l}\text { A potência fornecida ultrapassou poucas vezes de } 80 \% \text { da } \\
\text { capacidade de seu transformador. Nas poucas vezes em que } \\
\text { passou, a situação durou cerca de duas horas e não } \\
\text { ultrapassou } 130 \% \text {. O transformador satisfaz as condições } \\
\text { propostas. }\end{array}$ \\
\hline Observatório Sismológico & $\begin{array}{l}\text { A potência fornecida mantém-se menor que } 20 \% \text { da } \\
\text { capacidade do transformador durante todo o mês. Nem em } \\
\text { meses de consumo recorde, o carregamento ultrapassa essa } \\
\text { porcentagem. O transformador satisfaz as condições } \\
\text { propostas, podendo até mesmo ser considerado } \\
\text { superdimensionado caso esteja alimentando somente o local } \\
\text { monitorado. }\end{array}$ \\
\hline
\end{tabular}




\begin{tabular}{|c|c|}
\hline ICC Sul e Reitoria & $\begin{array}{l}\text { Em nenhum momento ultrapassou-se o valor de } 80 \% \text { de } \\
\text { nenhum dos } 3 \text { transformadores que alimentam os dois prédios } \\
\text { em questão. Em caso de falha de um dos transformadores, é } \\
\text { possível que os outros dois alimentem toda a carga dos dois } \\
\text { prédios em caráter emergencial sem maiores conseqüências. } \\
\text { Em poucos momentos o carregamento dos } 3 \text { transformadores } \\
\text { somada ultrapassou } 100 \% \text { da potência nominal de } 2 \\
\text { transformadores. Os transformadores satisfazem as condições } \\
\text { propostas. }\end{array}$ \\
\hline ICC Norte e BCE & $\begin{array}{l}\text { Os três transformadores permanecem com a carga entre } 40 \% \\
\text { e } 60 \% \text { de suas potências nominais, mas caso haja falha em } \\
\text { um dos transformadores, os outros dois transformadores } \\
\text { poderão ter que operar ininterruptamente com carga superior } \\
\text { a } 80 \% \text {, situação que deveria ser evitada. É necessário um } \\
\text { estudo mais aprofundado para apurar o que pode ser feito por } \\
\text { essa subestação. }\end{array}$ \\
\hline Faculdade de Educação 01 & $\begin{array}{l}\text { Em nenhum momento ultrapassou } 20 \% \text { da potência nominal } \\
\text { do transformador. O transformador satisfaz as condições } \\
\text { propostas e pode até ser considerado superdimensionado, } \\
\text { caso esteja alimentando somente a área monitorada. }\end{array}$ \\
\hline Faculdade de Tecnologia & $\begin{array}{l}\text { O transformador de } 500 \mathrm{kVA} \text { de potência nominal } \\
\text { dificilmente tem mais de } 40 \% \text { de sua carga em carregamento, } \\
\text { e mesmo essas situações não duram mais de uma hora. Os } \\
\text { transformadores de } 150 \mathrm{kVA} \text { de carga nominal não tiveram } \\
\text { em nenhum momento carregamento superior a } 20 \% \text { de sua } \\
\text { carga nominal. Os transformadores satisfazem as condições } \\
\text { propostas, mas em caso de defeito em qualquer um deles, os } \\
\text { outros não podem suprir seu carregamento por não estarem } \\
\text { próximos. }\end{array}$ \\
\hline
\end{tabular}




\begin{tabular}{|c|c|}
\hline Faculdade de Educação 03/05 & $\begin{array}{l}\text { Somente em uma ocasião, por cerca de } 15 \text { minutos, foi } \\
\text { ultrapassada } 50 \% \text { da potência nominal do transformador, } \\
\text { durante o resto do mês, não ultrapassou-se esta barreira. O } \\
\text { transformador satisfaz as condições propostas e pode ser } \\
\text { considerado superdimensionado, caso esteja alimentando } \\
\text { somente a área monitorada. }\end{array}$ \\
\hline Faculdade de Medicina/Faculdade de Saúde & $\begin{array}{l}\text { Em poucos momentos do mês ultrapassou-se a barreira de } \\
30 \% \text { da carga nominal de cada um dos dois transformadores. } \\
\text { Nenhum dos momentos superou uma hora de duração. Caso } \\
\text { haja defeito em um dos transformadores, o outro pode ser } \\
\text { utilizado para alimentar a carga total indefinidamente, visto } \\
\text { que mesmo em condições de pico de consumo, não } \\
\text { ultrapassa-se } 70 \% \text { de sua potência nominal. Os } \\
\text { transformadores satisfazem as condições propostas e podem } \\
\text { ser considerados superdimensionados, caso esteja } \\
\text { alimentando somente a área monitorada. }\end{array}$ \\
\hline CEPLAN & $\begin{array}{l}\text { O consumo de ambos os prédios do CEPLAN não ultrapassa } \\
10 \% \text { da carga nominal de seu transformador em momento } \\
\text { algum do mês. O transformador satisfaz as condições } \\
\text { propostas e pode ser considerado superdimensionado, caso } \\
\text { esteja alimentando somente a área monitorada. }\end{array}$ \\
\hline CEFTRU & $\begin{array}{l}\text { Poucas vezes durante o mês, com duração de } 15 \text { minutos, } \\
\text { ultrapassou-se } 25 \% \text { da potência nominal do transformador. O } \\
\text { transformador satisfaz as condições propostas e pode ser } \\
\text { considerado superdimensionado, caso esteja alimentando } \\
\text { somente a área monitorada. }\end{array}$ \\
\hline
\end{tabular}




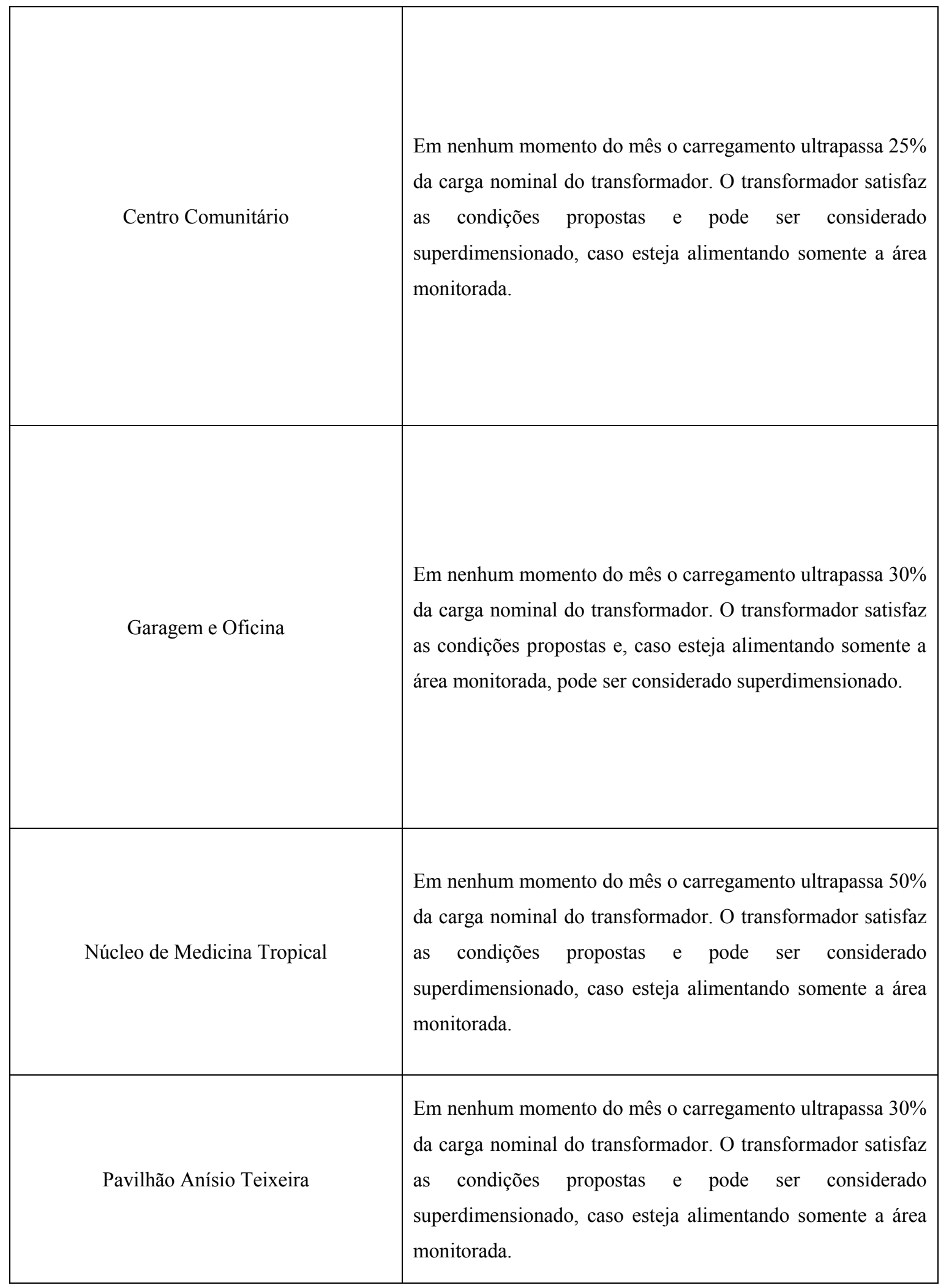




\begin{tabular}{|c|c|}
\hline Pavilhão João Calmon & $\begin{array}{l}\text { Em nenhum momento do mês o carregamento ultrapassa } 30 \% \\
\text { da carga nominal do transformador. O transformador satisfaz } \\
\text { as condições propostas e pode ser considerado } \\
\text { superdimensionado, caso esteja alimentando somente a área } \\
\text { monitorada. }\end{array}$ \\
\hline Multiuso I & $\begin{array}{l}\text { Em poucos picos de cerca de } 30 \text { minutos de duração o } \\
\text { carregamento ultrapassa } 50 \% \text { da carga nominal do } \\
\text { transformador. O transformador satisfaz as condições } \\
\text { propostas e pode ser considerado superdimensionado, caso } \\
\text { esteja alimentando somente a área monitorada. }\end{array}$ \\
\hline Multiuso II & $\begin{array}{l}\text { Mantém-se o carregamento menor que } 50 \% \text { da potência } \\
\text { nominal do transformador por maior parte do tempo, havendo } \\
\text { ocasionais picos que não ultrapassam } 60 \% \text {. O transformador } \\
\text { satisfaz as condições propostas e pode ser considerado } \\
\text { superdimensionado, caso esteja alimentando somente a área } \\
\text { monitorada. }\end{array}$ \\
\hline FACE & $\begin{array}{l}\text { Em nenhum momento } 25 \% \text { da carga nominal dos dois } \\
\text { transformadores é ultrapassada, sendo assim, caso haja } \\
\text { defeito em um deles, o outro transformador pode facilmente } \\
\text { alimentar o prédio inteiro mesmo por longos períodos. Os } \\
\text { transformadores satisfazem as condições propostas e podem } \\
\text { ser considerados superdimensionados, caso estejam } \\
\text { alimentando somente a área monitorada. }\end{array}$ \\
\hline Prefeitura & $\begin{array}{l}\text { Em nenhum momento do mês o carregamento ultrapassa } 40 \% \\
\text { da carga nominal do transformador. O transformador satisfaz } \\
\text { as condições propostas e pode ser considerado } \\
\text { superdimensionado, caso esteja alimentando somente a área } \\
\text { monitorada. }\end{array}$ \\
\hline
\end{tabular}




\begin{tabular}{|c|c|}
\hline Restaurante Universitário & $\begin{array}{l}\text { Em nenhum momento do mês o carregamento ultrapassa } 10 \% \\
\text { da carga nominal do transformador. O transformador satisfaz } \\
\text { as condições propostas e pode ser considerado } \\
\text { superdimensionado, caso esteja alimentando somente a área } \\
\text { monitorada. }\end{array}$ \\
\hline SG-01 & $\begin{array}{l}\text { Em nenhum momento do mês o carregamento ultrapassa } 20 \% \\
\text { da carga nominal do transformador. O transformador satisfaz } \\
\text { as condições propostas e pode ser considerado } \\
\text { superdimensionado, caso esteja alimentando somente a área } \\
\text { monitorada. }\end{array}$ \\
\hline SG-09 & $\begin{array}{l}\text { Em poucos momentos do mês o carregamento ultrapassa } 40 \% \\
\text { da carga nominal do transformador e mesmo nos períodos } \\
\text { nos quais ultrapassa, não chega a } 50 \% \text {. O transformador } \\
\text { satisfaz as condições propostas e pode ser considerado } \\
\text { superdimensionado, caso esteja alimentando somente a área } \\
\text { monitorada. }\end{array}$ \\
\hline SG-12 & $\begin{array}{l}\text { Em nenhum momento do mês o carregamento ultrapassa } 50 \% \\
\text { da carga nominal do transformador. O transformador satisfaz } \\
\text { as condições propostas e, caso esteja alimentando somente a } \\
\text { área monitorada, pode ser considerado superdimensionado. }\end{array}$ \\
\hline SG-11 & $\begin{array}{l}\text { Em seus momentos de pico, o carregamento chega a } 70 \% \text { da } \\
\text { carga nominal do transformador e está normalmente acima de } \\
50 \% \text { em horário de aulas. O transformador satisfaz as } \\
\text { condições propostas. }\end{array}$ \\
\hline Geocronologia & $\begin{array}{l}\text { Em nenhum momento do mês o carregamento ultrapassa } 10 \% \\
\text { da carga nominal do transformador. O transformador satisfaz } \\
\text { as condições propostas e pode ser considerado } \\
\text { superdimensionado, caso esteja alimentando somente a área } \\
\text { monitorada. }\end{array}$ \\
\hline Instituto de Química & $\begin{array}{l}\text { Não é possível avaliar o prédio em questão pelo fato de ainda } \\
\text { não ter sido inaugurado. Seu consumo é extremamente baixo, } \\
\text { por só alimentar alguns instrumentos de construção para } \\
\text { acabamento. }\end{array}$ \\
\hline
\end{tabular}




\begin{tabular}{|l|l|}
\hline CESPE & $\begin{array}{l}\text { Consumo menor que 5\% da potência nominal de seus dois } \\
\text { transformadores. Os transformadores satisfazem as condições } \\
\text { propostas e podem ser considerados superdimensionados, } \\
\text { caso estejam alimentando somente a área monitorada. }\end{array}$ \\
\hline
\end{tabular}

\subsubsection{Análise dos dados}

Verificando os resultados expostos na Tabela 4.2, percebemos que, ao menos no mês de Março, a situação estava bem confortável para o carregamento na maioria dos prédios. Entretanto, uma análise contínua desses carregamentos se faz necessária, tendo em vista que nos meses finais do período de seca em Brasília, que nos últimos anos têm sido Setembro e Outubro, o consumo de energia aumenta de forma considerável devido ao uso intenso de aparelhos de ar condicionado. No ano de 2007 o carregamento dos transformadores dos prédios Sul e Norte do ICC chegou a níveis tão altos que foi necessário solicitar que não fossem ligados aparelhos de ar condicionado. Uma análise mensal simples como a feita acima auxilia na previsão e solução de problemas como o apresentado acima.

Um caso a ser estudado com maior cuidado é a subestação do ICC Norte, já que mesmo durante o mês de Março, caso haja alguma falha em um dos três transformadores, não há como os dois restantes suportarem o carregamento por um longo período de tempo sem perda da vida útil. O mês de Março mesmo se tratando de um mês letivo, costuma possuir um consumo baixo quando comparados aos meses de Setembro e Outubro.

\subsection{NAVEGAÇÃO SIMPLIFICADA}

Uma das contribuições propostas nesse trabalho é permitir que outros usuários da área administrativa possam acessar o sistema CCK para checar informações simples, como tensão, corrente e potência, ou algumas mais aprofundadas caso seja necessário. Para permitir que qualquer usuário possa acessar essas informações de forma fácil e intuitiva, um ambiente simplificado, visualmente agradável e praticamente auto-explicativo se faz 
necessário. Partindo dessas premissas, foi feita uma reestruturação do menu Diagramas do software CCK descrito no Capítulo 3.

\subsubsection{A visualização do Campus}

Anteriormente, a visualização inicial que tínhamos do Campus da UnB, no ambiente Diagramas era a seguinte:

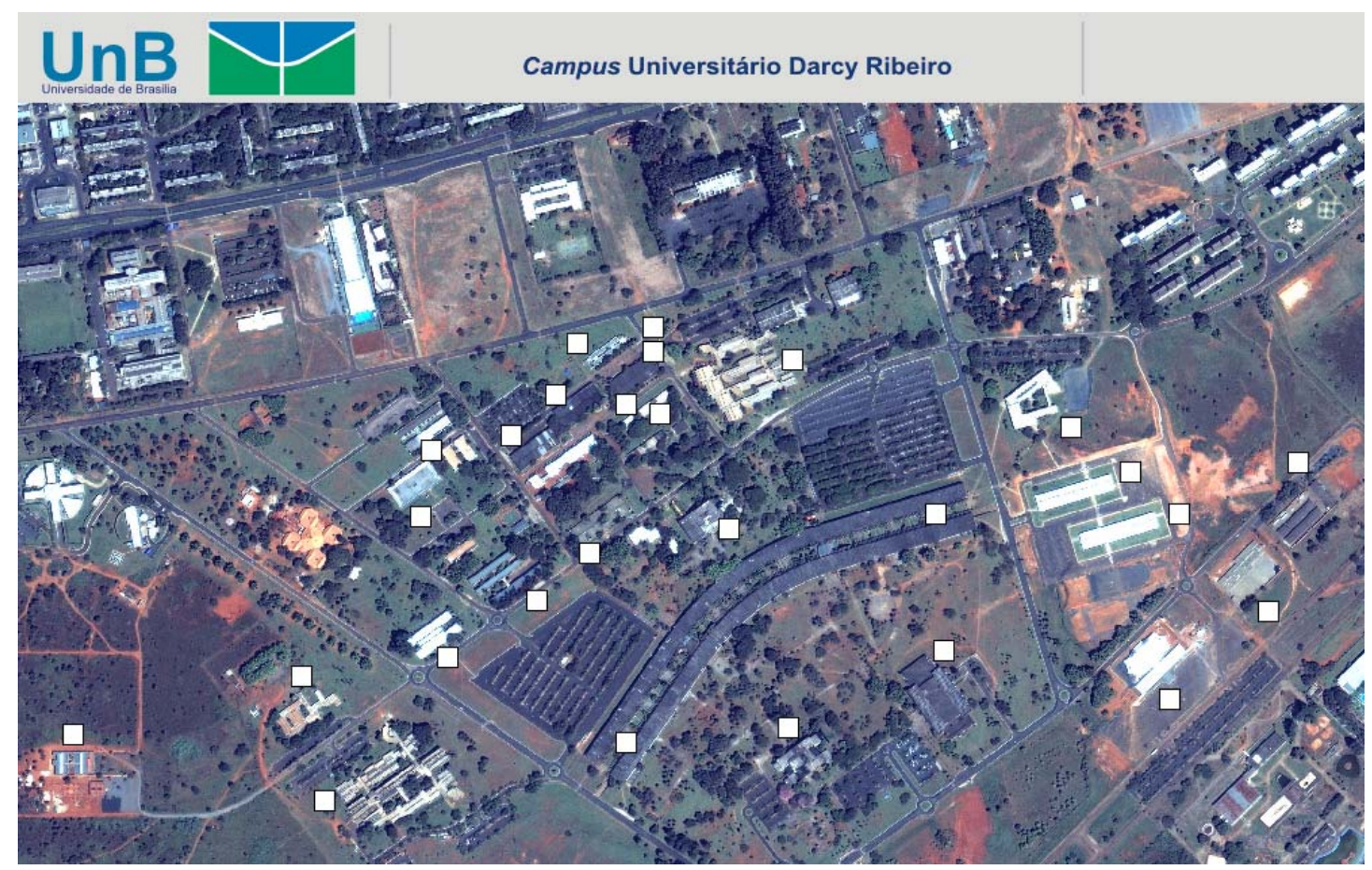

Figura 4.1 - Visão aérea do Campus Darcy Ribeiro.

A visualização da Figura 4.1 trazia vários problemas. A resolução da foto, obtida no próprio site da Universidade, era muito baixa, na tela do computador tornava-se "pixelada". Cada quadrado branco na figura refere-se a um prédio monitorado, mas não há identificação clara de qual prédio é cada uma das construções, dificultando sua localização. Elementos da paisagem como árvores, caminhos de barro e outros poluem a imagem, tornando-a confusa. 
A solução encontrada foi vetorizar a vista aérea do Campus e diagramar os locais que estão sendo monitorados pelo sistema CCK. Fazendo isso, é possível ajustar a figura para qualquer resolução. Após a vetorização e trabalho em cima da imagem, o resultado foi a figura a seguir.

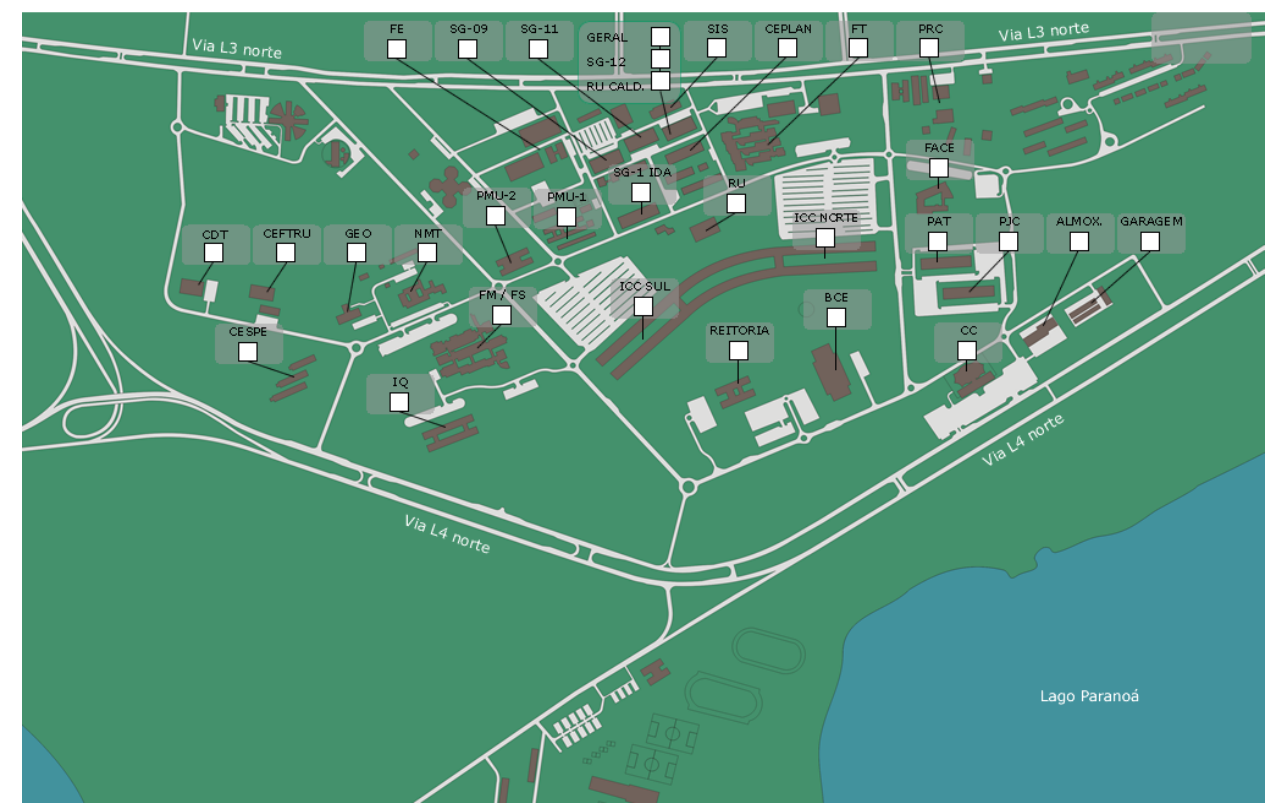

Figura 4.2 - Visão aérea vetorizada do Campus Darcy Ribeiro.

Após a vetorização e diagramação do mapa, a visão aérea do Campus, Figura 4.2, tornou-se pouco poluída visualmente, com os prédios em destaque e locais monitorados indicados por traços e nomeados. Dessa forma, é possível encontrar e selecionar facilmente o local monitorado. Para não poluir a imagem, foram feitas abreviações de alguns nomes.

Ao acessar os prédios monitorados também havia problemas, as únicas imagens disponíveis eram ampliações do mapa principal, o que resultava em imagens "pixeladas". 


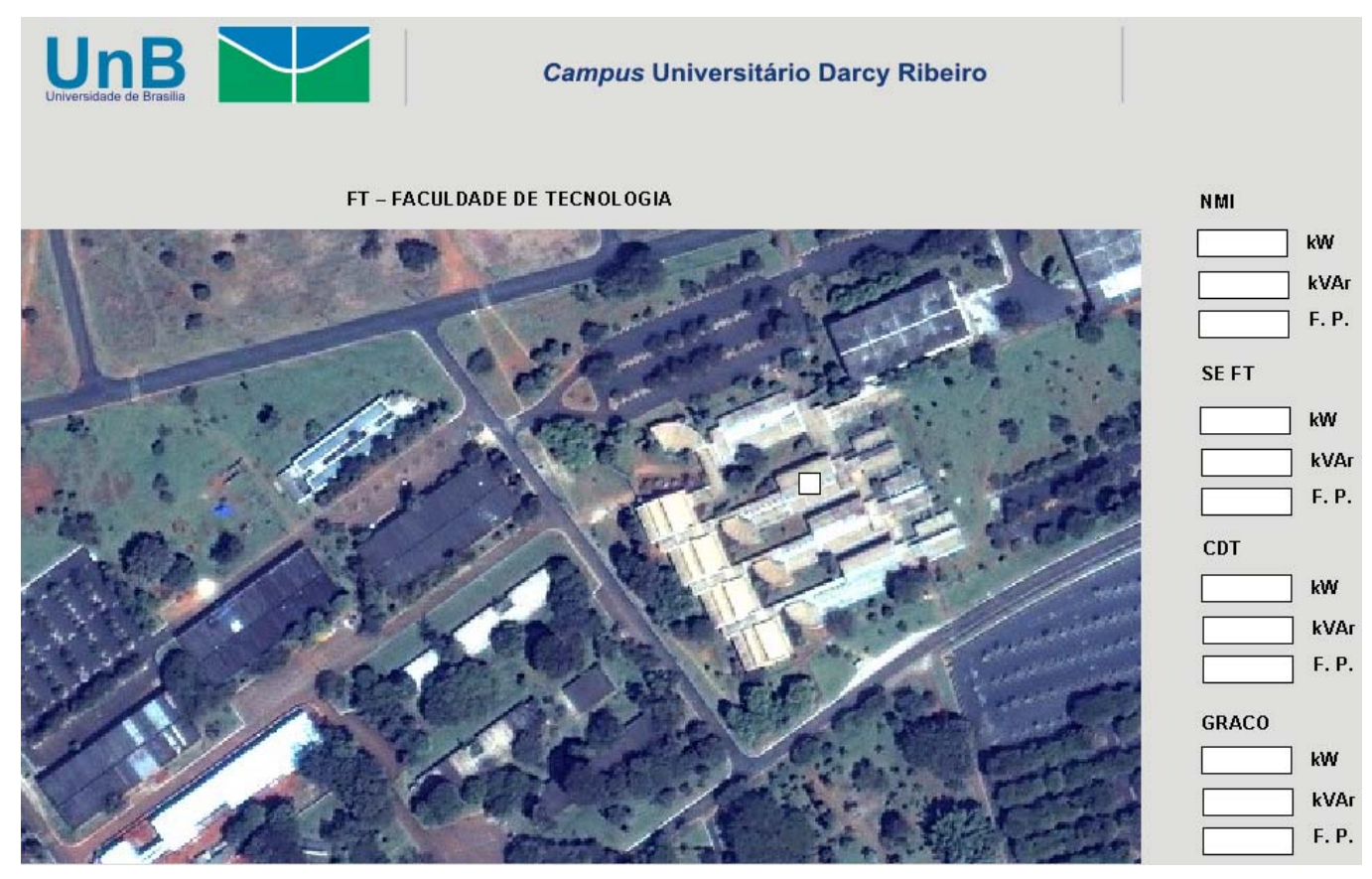

Figura $\quad 4.3$ - Aparência antiga da figura referente à Faculdade de Tecnologia.

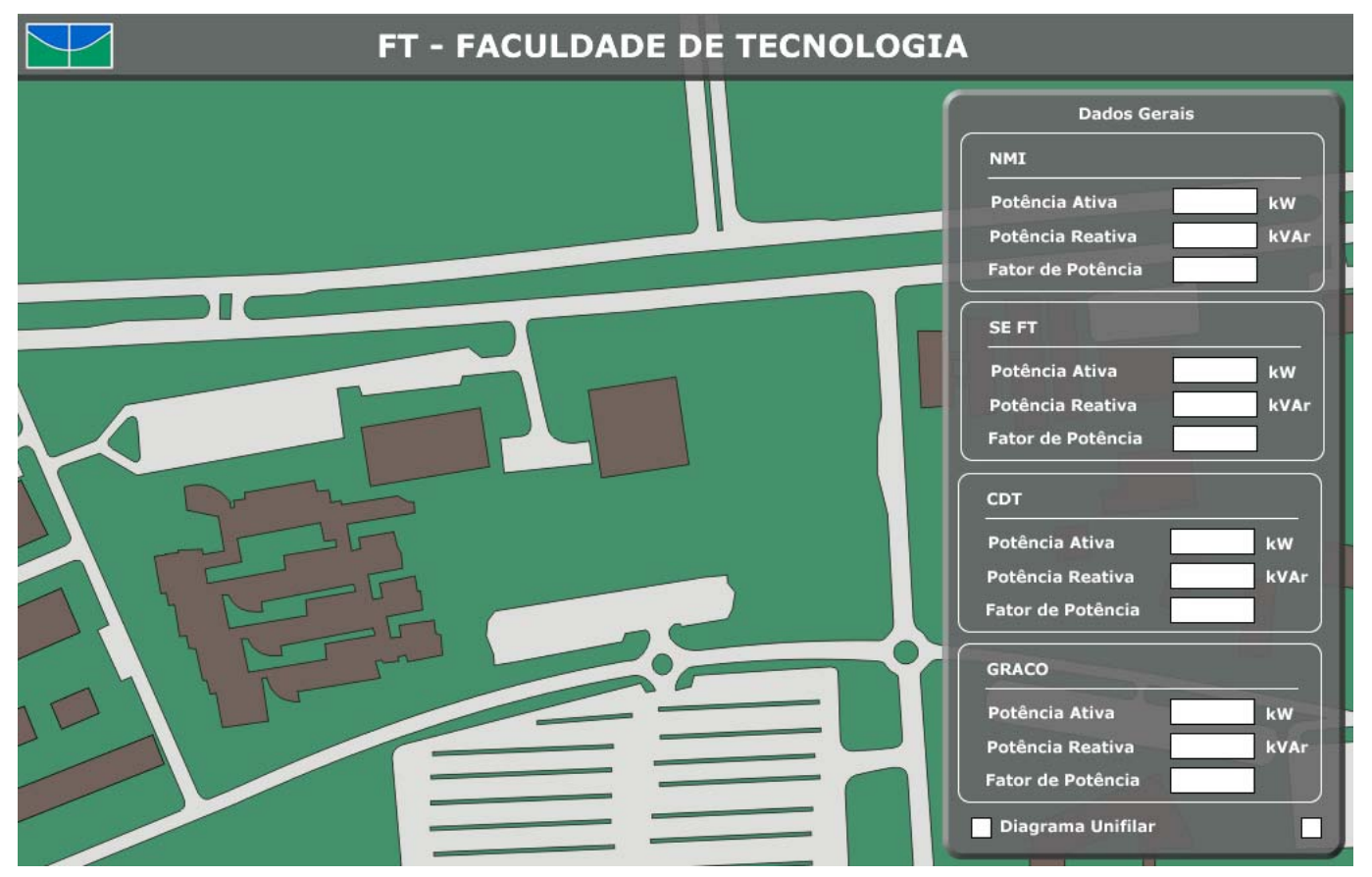

Figura 4.4 - Nova tela da Faculdade de Tecnologia no menu Diagramas. 
Como a visão aérea do Campus Darcy Ribeiro estava vetorizada, era possível ampliá-la no local onde estão sendo feitas as leituras. Padronizou-se também a forma como são apresentados os dados nas unidades monitoradas, conforme pode ser visto na figura 4.4.

Agora há uma visão bem mais limpa de uma versão simplificada do prédio. Os dados apresentados agora são padronizados, sempre contidos em uma barra vertical cinza situada à direita da figura, com os transformadores discriminados e com molduras brancas.

Os diagramas unifilares também foram padronizados e modificados. Anteriormente, esses eram apresentados como na Figura 4.5 a seguir.

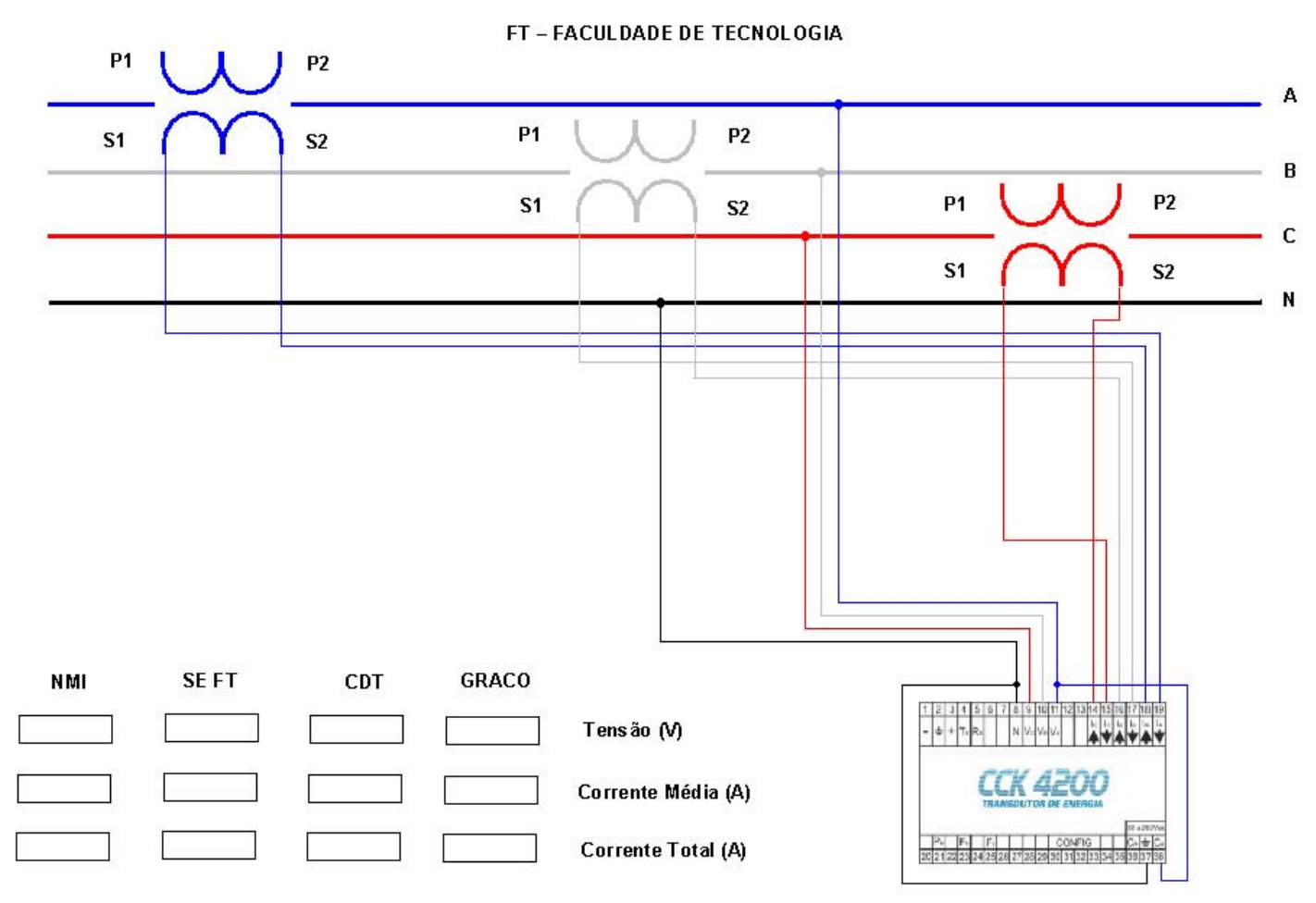

Figura $\quad 4.5$ - Antiga apresentação do diagrama unifilar da Faculdade de Tecnologia.

No caso do diagrama unifilar, por já se tratar de uma figura esquematizada, poucas modificações foram feitas. Ajustou-se a resolução das imagens para que não houvesse "pixelização", como ocorria com os transformadores indicados na Figura 4.5 entre as denominações P1, P2, S1 e S2. Adotou-se também a norma para cor do Neutro, como 
sendo azul claro e, para as fases A, B e C, adotou-se preto, branco e vermelho, respectivamente.

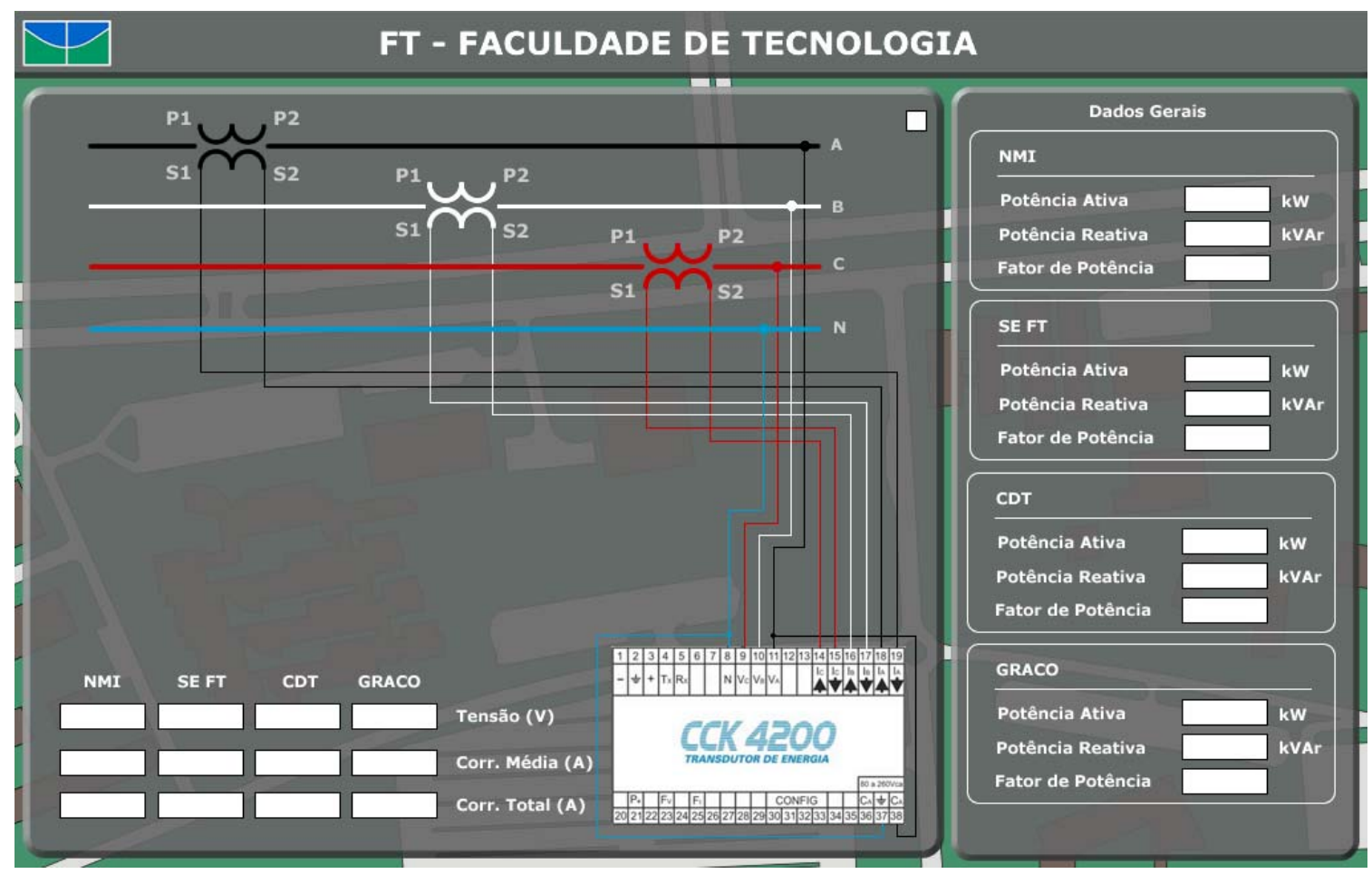

Figura 4.6 - Nova apresentação do diagrama unifilar da Faculdade de Tecnologia.

\subsubsection{Conclusão}

Com um aprimoramento do menu Diagramas é possível que qualquer usuário possa utilizar o sistema de monitoramento do consumo do Campus mais facilmente, tornando sua navegação mais agradável.

\subsection{GERANDO FATURAS}

Conforme foi apresentado no tópico 3.3.2 do capítulo anterior, o software CCK permite a emissão de relatórios semelhantes às faturas emitidas por concessionárias, embora de maneira muito limitada. Porém, com auxílio da programação em VBA, através da criação de Macros, as quais são inseridas no EXCEL, foi possível gerar contas com 
dados dos meses anteriores de consumo para todos os Centros de Custo da Universidade de Brasília.

Para comprovar a precisão das faturas emitidas pelo sistema, comparou-se as faturas da CEB, obtidas na Prefeitura do Campus com uma conta referente ao mesmo período emitida no menu Rateio do software CCK. Os resultados são bastante próximos, só não obtendo precisão de $100 \%$ por não ser possível determinar o horário exato nos quais foram feitas as leituras da CEB, somente os dias. Como exemplo, pode-se observar o Anexo A, referente à conta da Medição Geral emitida pela $\mathrm{CEB}$ e o Anexo $\mathrm{B}$, referente à fatura emitida pelo Software CCK. Os valores das contas são R\$ 344.121,23 e R\$ 342.233,60, um erro de cerca de $0,55 \%$.

\subsubsection{Premissas}

Para a emissão de faturas por Centro de Custo, tivemos que partir de diversas premissas:

- Os períodos para gerar conta foram padronizados, sempre partindo da hora 00:00 do primeiro dia do mês, até a hora 00:00 do primeiro dia do mês seguinte, com exceção do mês de dezembro, pois, como o software não permite a leitura de um período que inicie e termine em anos diferentes, limitou-se seu período da hora 00:00 do dia 01/12 até a hora 23:59 do dia 31/12.

- Desconsiderou-se a cobrança por iluminação pública, pois não é possível sua inclusão em faturas específicas. Ou define-se esta para todos os centros de custo, ou para nenhum.

Se essa cobrança fosse mantida, seria repetida para cada centro de custo, resultando em uma cobrança total por iluminação pública mais de 20 vezes maior do que deveria ser.

Como essa exclusão só resulta em um erro menor do que $0,2 \%$ da conta total optouse por realizá-la.

- Na fatura emitida pela CEB há quatro taxas que resultam em desconto. Nem todas podem ser adicionadas na geração de tarifa do CCK, mas há um campo designado para 
DESCONTO que permite que seja definido um percentual de desconto. Como todos os descontos das taxas são em porcentagens do total da conta, não acumulativos, somou-se seus percentuais e definimos o resultado como o desconto total, que é de 5,85\%.

-Para definir as demandas contratadas em Ponta e Fora de Ponta dos centros de custo, observaram-se as demandas máximas durante os meses de consumo normal no ano de 2007, assumindo um valor cerca de $10 \%$ acima do consumo normal de Ponta e Fora de Ponta.

\subsubsection{Procedimento para geração de fatura}

Inicialmente, partiu-se do pré-suposto que o sistema CCK esteja configurado corretamente e que os arquivos e pastas necessários não tenham sido alterados a fim de permitir o correto funcionamento não somente daquele sistema como também da Macro, programa desenvolvido em VBA.

Passa-se então à descrição dos procedimentos necessários para geração da faturas:

\section{a) Abrir o Sistema de Rateio de Custo do CCK}

b) No menu Emissão Contas selecione a opção Global para a geração de faturas das unidades consumidoras, Medição Geral e RU Caldeiras. Selecione a opção Por Centro de Custo para geração de fatura das edificações restantes.

c) Seleciona na tela seguinte o mês, ano e edificação desejados e pressione o botão Processa.

d) Na nova tela que será exibida pressione o botão Excel, situado na barra inferior da tela, e um arquivo de EXCEL será gerado.

e) Salve este arquivo seguindo o modelo:

(mês)_(ano)_(local ).xls na pasta C:|CCK|Faturas $|(a n o)|(m e ̂ s) \_(a n o) \mid$

- O mês deve ser numérico e não deve conter zero à esquerda

-O ano deve ser numérico e completo, possuindo quatro dígitos 
-O local deve seguir a nomenclatura apontada no Anexo C.

Ex.: C:\CCK\Faturas $\backslash 2008 \backslash 3$ _2008\3_2008_almox.xls

Este arquivo refere-se à fatura relativa ao mês de março de 2008 do Almoxarifado

f) Repita os procedimentos de a) a e) para todos os locais indicados no Anexo D.

g) Abra o arquivo GeradorDeFaturas.xls localizado na pasta $\mathrm{C}: \mathrm{ICCK} \backslash$ Faturas e prescione simultaneamente as teclas $\mathrm{CTRL}+\mathrm{SHIF}+\mathrm{M}$ para executar a Macro e a seguinte tela será exibida.

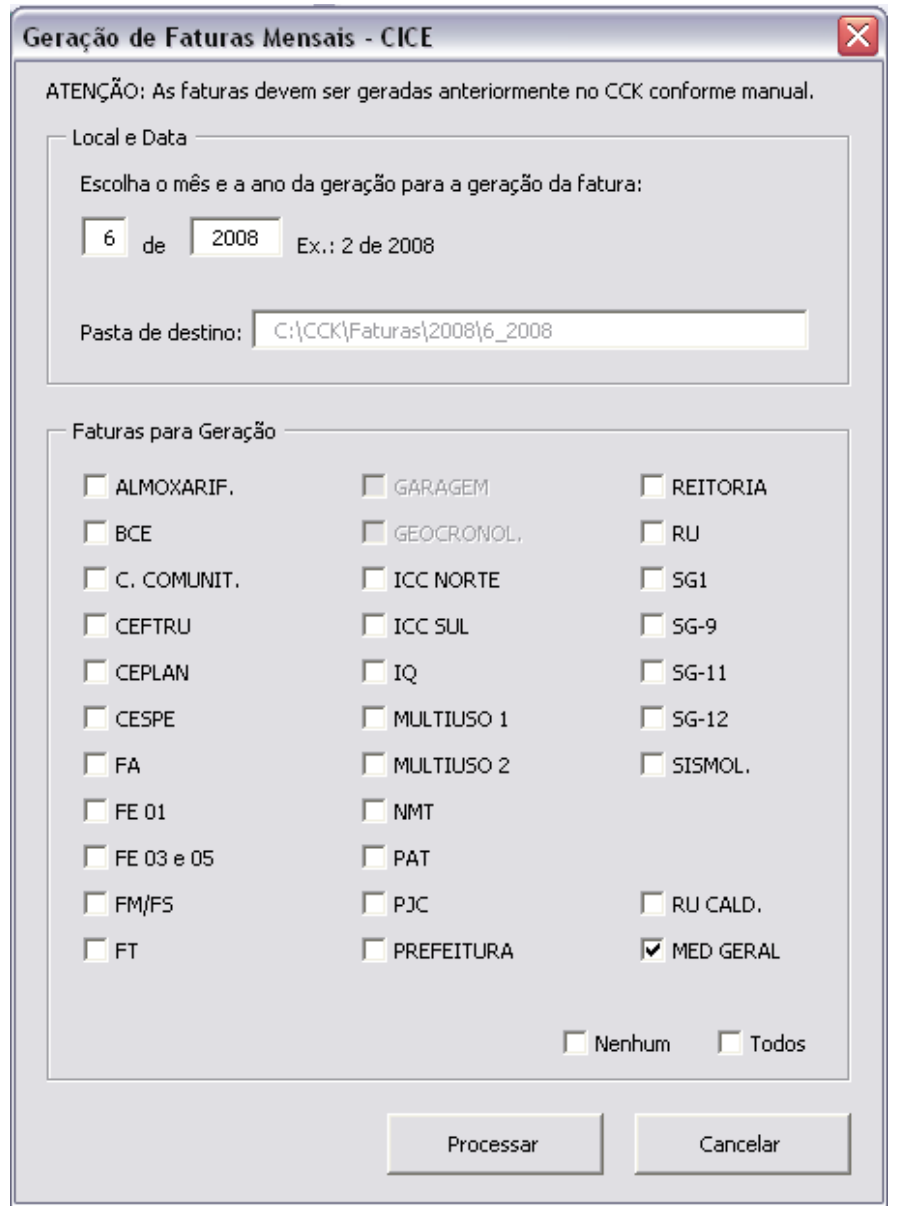

Figura $\quad 4.7$ - Tela da Macro.

h) Siga as instruções constantes na figura 4.7. Observe que os locais GARAGEM e GEOCRONOL. não podem ser marcados. Isto ocorre sempre que os arquivos referentes 
àqueles locais não estiverem disponíveis. As causas desta tipo ocorrência podem ser: arquivos salvos em local incorreto, inexistentes ou não nomeados conforme item e).

i) Clique no botão Processar para gerar as faturas e aguarde o processamento. Os arquivos gerados serão salvos automaticamente na Pasta de Destino com os mesmo nomes dos arquivos de origem acrescido da palavra Fatura. Por exemplo:

C:ICCK $\backslash$ Faturas $\backslash 2008 \backslash 3 \_2008 \backslash$ Fatura_3_2008_almox.xls

As faturas geradas podem ser então acessadas e impressas como qualquer arquivo de EXCEL.

\subsubsection{Funcionalidades da fatura}

A fatura gerada trás uma série de informações relevantes à gestão do consumo da energia elétrica na UnB. Uma delas é um histórico do consumo dos dois meses anteriores ao atual e ainda uma série de amostras estatísticas como pode ser visualizado no Anexo D.

\subsubsection{Conclusões}

Essa ferramenta permitiu a geração de uma fatura mais completa que a apresentada pelo sistema de monitoramento, como um acompanhamento da evolução do consumo. Permite também que sejam geradas as faturas completas de todos os locais monitorados simultaneamente. O conhecimento da evolução da fatura é imprescindível para que haja gestão do consumo.

\subsection{ESTATÍSTICAS DE CONSUMO}

Com os dados do consumo mensal de edificações obtidos no sistema de monitoramento e de posse do número de alunos, docentes e funcionários técnicoadministrativos conseguidos junto à Administração do Campus, é possível gerar estatísticas sobre o consumo de energia elétrica mensal por categoria. 


\subsubsection{Premissas}

Considerou-se para o cálculo dessas estatísticas que toda a energia consumida no prédio do Instituto de Artes (SG1) foi utilizada por funcionários, docentes e alunos dos:

- Departamento de Artes Cênicas,

- Departamento de Artes Visuais,

- Departamento de Desenho Industrial,

- Departamento de Música.

Da mesma forma, para a energia consumida na FT, SG11 e SG12, considerou-se os alunos, docentes e funcionários dos:

- Departamento de Engenharia Civil e Ambiental,

- Departamento de Engenharia Elétrica,

- Departamento de Engenharia Florestal,

- Departamento de Engenharia Mecânica

- CDT, que situa-se no Departamento de Engenharia Elétrica.

Esses edifícios foram escolhidos também pela possibilidade de determinar de forma mais precisa os cursos que os utilizam. Prédios como o ICC, por exemplo, são utilizados por alunos de diversos cursos, sendo difícil determinar sem estudo mais aprofundado a circulação de alunos.

\subsubsection{Resultados Obtidos}

Para exemplificar essa estatística, foram escolhidos os prédios apresentados em 4.5.1 justamente pelas naturezas distintas dos cursos lá lecionados. Enquanto no SG1 as aulas não necessitam de recursos diferenciados, os cursos lecionados nos outros edifícios apresentados são da área de tecnologia, necessitando de laboratórios e diversos equipamentos movidos a energia elétrica. $\mathrm{O}$ período utilizado para análise foi o mês de Março de 2008. O resultado obtido está na Tabela 4.3 abaixo. 
Tabela 4.3 - Consumo por pessoa em Março de 2008 nos prédios SG1, FT, SG11 e SG12.

\begin{tabular}{|c|c|c|c|c|}
\hline Edifício & Categoria & $\begin{array}{c}\text { Número de } \\
\text { pessoas }\end{array}$ & $\begin{array}{l}\text { Consumo } \\
\text { (kWh) }\end{array}$ & $\begin{array}{c}\text { Consumo por } \\
\text { categoria } \\
(\mathrm{kWh} / \text { pessoa })\end{array}$ \\
\hline \multirow{3}{*}{ SG1 } & Aluno & 1730 & \multirow{3}{*}{5114} & 2,956 \\
\hline & Docente & 81 & & 63,136 \\
\hline & $\begin{array}{c}\text { Funcionário técnico- } \\
\text { administrativo }\end{array}$ & 23 & & 222,348 \\
\hline \multirow{3}{*}{$\begin{array}{c}\text { FT } \\
\text { SG11 } \\
\text { SG12 }\end{array}$} & Aluno & 2621 & \multirow{3}{*}{128345} & 48,968 \\
\hline & Docente & 161 & & 797,174 \\
\hline & $\begin{array}{c}\text { Funcionário técnico- } \\
\text { administrativo }\end{array}$ & 57 & & 2251,667 \\
\hline
\end{tabular}

\subsubsection{Conclusões}

Pode-se perceber que o consumo por pessoa na área de tecnologia é cerca de 24 vezes maior para alunos, e 10 vezes maior para docentes e funcionários técnicoadministrativo.

Esse resultado é interessante, no sentido de que um esforço maior para uma otimização de energia para a área de tecnologia se faz mais necessária que para a área de artes.

\subsection{CONSIDERAÇÕES FINAIS}

Nesse capítulo foram apresentadas as ferramentas geradas para possibilitar uma gestão inteligente do consumo de energia elétrica no Campus Darcy Ribeiro. 
Apresentou-se também pré-analises e sugestões de trabalhos que podem ser feitos com os dados coletados do sistema. 


\section{CONCLUSÃO}

Este trabalho apresentou ferramentas e análises a serem feitas para que haja uma gestão mais eficiente do consumo de energia elétrica no Campus Darcy Ribeiro. Várias dificuldades foram encontradas, devido ao sistema ainda não estar otimizado para as necessidades da UnB, bem como uma falta de metodologia para uso dos dados que já eram coletados.

Foi possível com uma análise simples perceber problemas em alguns transformadores do Campus, que não são adequados ao carregamento que estes recebem. Verificou-se também que a área de Tecnologia consome uma quantidade sensivelmente maior de energia que a área de Artes, direcionando assim prioridades para quais grupos abordar primeiro em campanhas de educação de consumo.

Um estudo estatístico mais aprofundado pode possibilitar a criação de uma lista de prioridades para departamentos a serem abordados quanto à questão elétrica, caso não seja possível uma campanha para todo o Campus. Estudando também os transformadores e seus carregamentos ao longo dos anos, pode-se alcançar uma solução que não necessite da compra de novos equipamentos, mas sim em uma distribuição adequada dos já existentes. Outro estudo que pode ser feito sobre os transformadores, pelo fato de grande parte deles estar superdimensionada, é a análise das perdas relativas ao seu funcionamento.

Alcançou-se uma interface gráfica agradável e intuitiva, que agora permite que membros da UnB possam navegar pelo sistema sem dificuldades maiores e checarem em tempo real dados de suas edificações.

O sistema de rateio tornou-se mais eficiente, apresentando dados mais consistentes e permitindo comparações com meses anteriores. Uma distribuição de faturas para a diretoria dos locais monitorados pode alcançar uma conscientização maior quanto ao comportamento do local e, conseqüentemente medidas eficientes para uma economia de energia. Tais faturas podem também apontar os locais nos quais precisa-se dar maior atenção. 
De posse de todos os dados coletados nesse trabalho e das ferramentas aqui desenvolvidas, é possível que seja criada uma linha de Trabalhos de Conclusão de Curso visando uma análise semestral da situação do consumo do Campus, possibilitando assim que seja feita uma gestão eficiente sem maiores custos para a Universidade e com grandes benefícios acadêmicos. 


\section{REFERÊNCIAS BIBLIOGRÁFICAS}

AJS, AJS Engenharia e Informática Ltda.. Disponível em: $<$ http://www.ajs.com.br/vetorizacao/index.html> Acessado em: 06 de Junho de 2008.

ALMEIDA, João Carlos de Oliveira. Introdução do sistema de monitoração e gerenciamento digital em tempo real da rede elétrica do Campus da Universidade de Brasília - UnB. 2003. Dissertação (Mestrado em Engenharia Elétrica) - Programa de PósGraduação Engenharia Elétrica, Universidade de Brasília, Brasília.

ANEEL, Agência Nacional de Energia Elétrica. Disponível em: $<$ http://www.aneel.gov.br/area.cfm?idArea=494\&idPerfil=2> Acessado em: 28 de Maio de 2008.

ANEEL. Resolução n. 456 de novembro de 2000. Estabelece, de forma atualizada e consolidada, as Condições Gerais de Fornecimento de Energia Elétrica. Disponível em: $<$ http://www.aneel.gov.br/cedoc/bres2000456.pdf> Acessado em: 05 de Maio de 2008.

ASSOCIAÇÃO BRASILEIRA DE NORMAS TÉCNICAS. NBR 5416: Aplicações de cargas em transformadores de potência - Procedimento, 1997. 92p.

CCK Automação Ltda. Equipamentos e sistemas de Gerenciamento de Energia Elétrica e Utilidades. Disponível em: <http://www.cck.com.br/portugues/index.htm> Acessado em: 28 de Maio de 2008.

MUELLER, John Paul. Vba for Dummies. Editora John Wiley \& Sons: São Francisco,

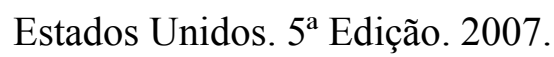

OLIVEIRA, L.S. Gestão do Consumo de Energia Elétrica no Campus da UnB. Dissertação de Mestrado em Engenharia Elétrica, Publicação PPGENE.DM-268/06, Departamento de Engenharia Elétrica, Universidade de Brasília, Brasília, DF, 2006.

UnB, Universidade de Brasília: História. Disponível em: $<$ http://www.unb.br/unb/historia/resumo.php> Acessado em: 25 de Maio de 2008. 
UnB, Universidade de Brasília: UnB em números. Disponível em: $<$ http://www.unb.br/numeros/index.php> Acessado em: 26 de Junho de 2008.

VETORIZAR. Disponível em: <http://www.vetorizar.com/vetorizar/definicao.htm> Acessado em: 06 de Junho de 2008. 


\section{ANEXOS}




\section{A. FATURA DA CEB RELATIVA AO MÊS DE MARÇO PARA MEDIÇÃO GERAL}

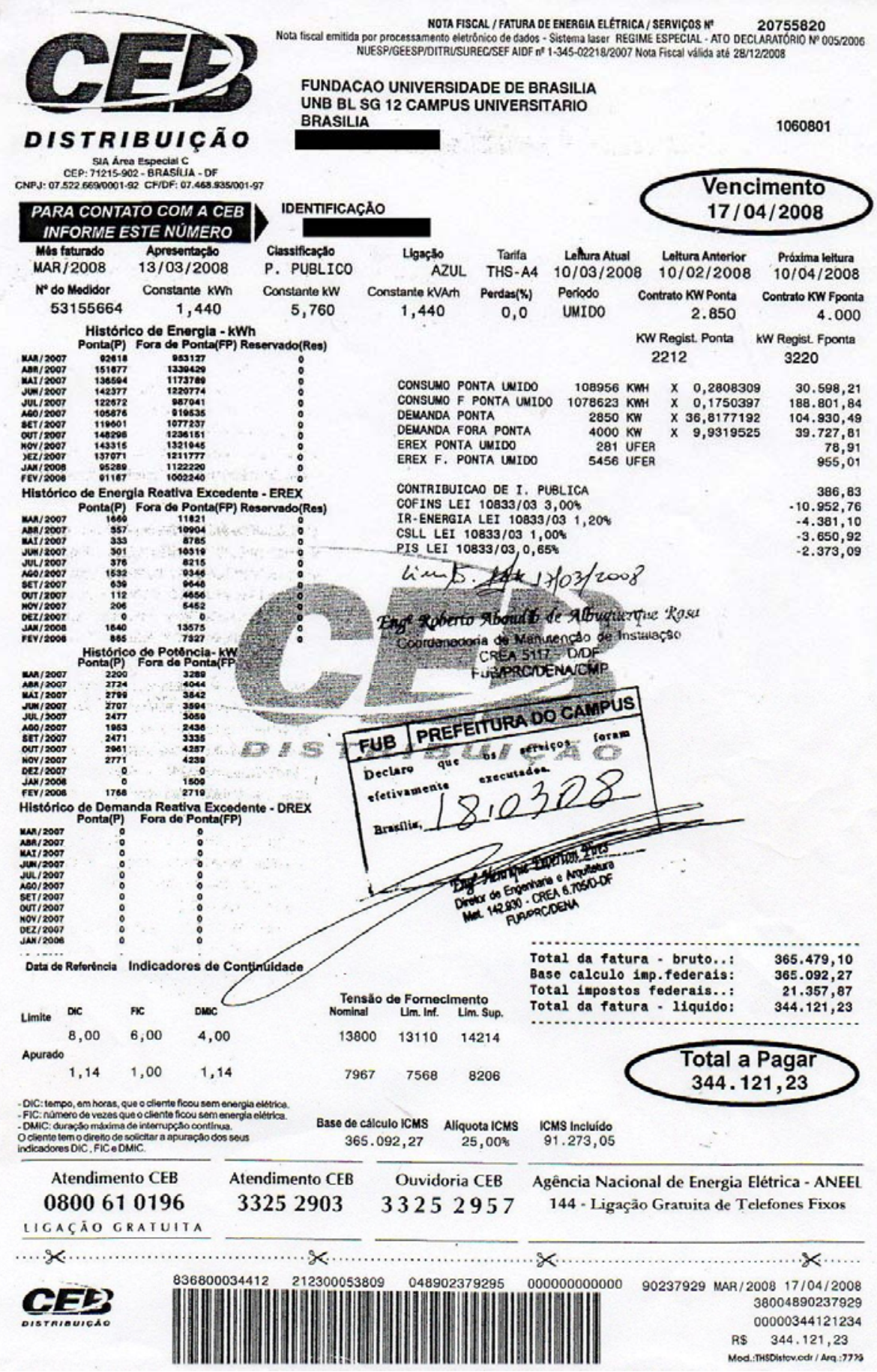




\section{B. FATURA DO CCK DO MÊS DE MARÇO PARA MEDIÇÃO GERAL}

\section{Conta Global MEDIÇÃO GERAL}

\begin{tabular}{|clcccc|}
\hline Demanda & $\begin{array}{l}\text { CT Ponta } \\
\text { CT }\end{array}$ & 2850 & Período & Inicial & $10 / 02 / 2008$ ás 00:00 \\
$(\mathrm{KW})$ & F.Ponta: & 4000 & & Final & $10 / 03 / 2008$ ás 00:00 \\
\hline
\end{tabular}

\begin{tabular}{|l|r|r|r|r|}
\hline Descriçao & Registrado & Faturado & \multicolumn{1}{|l|}{ Tarifa } & \multicolumn{1}{l|}{ Valores (R\$) } \\
\hline PONTA & & & & \\
- DEMANDA (KW) & 2212 & 2850 & 36,82 & 104930,50 \\
- ULTRAPASSAGEM & 0 & 0 & 0,00 & 0,00 \\
- CONSUMO & 108955 & & 280,83 & 30597,85 \\
(KWh) & 0 & 280,83 & 0,00 \\
- UFER & 0 & 36,82 & 0,00 \\
\hline - UFDR & 0 & & 127599,94 \\
\hline \multicolumn{2}{|r|}{} \\
\cline { 2 - 4 }
\end{tabular}

\begin{tabular}{|l|r|r|r|r|}
\hline Descriçao & Registrado & Faturado & Tarifa & \\
\hline F.PONTA & & & & \\
- DEMANDA (KW) & 3220 & 4000 & 9,93 & 0,00 \\
- ULTRAPASSAGEM & 0 & 0 & 0,00 & 188242,09 \\
- CONSUMO & 1075425 & & 0,00 \\
(KWh) & 0 & 0 & 175,04 & 0,00 \\
- UFER Indutivo & 0 & 9,93 & 175,04 \\
- UFDR Indutivo & 0 & 9,93 & 214633,66 \\
\hline - UFER Capacitivo & & & TOTAL \\
- UFDR Capacitivo & & & \\
\hline \multicolumn{2}{|r|}{}
\end{tabular}

\begin{tabular}{|l|r|}
\hline \multicolumn{2}{|l|}{ PONTA } \\
\hline - FATOR CARGA & 82 \\
\hline - CUSTO: & \\
R\$/MWh & $1.243,90$ \\
\hline - TOTAL DE HORAS & $60: 00$ \\
\hline
\end{tabular}

\begin{tabular}{|c|c|}
\hline \multicolumn{2}{|l|}{ F. PONTA } \\
\hline - FATOR CARGA & 53 \\
\hline $\begin{array}{l}\text { - CUSTO: } \\
\text { R\$/MWh }\end{array}$ & 211,98 \\
\hline - TOTAL DE HORAS & $636: 00$ \\
\hline
\end{tabular}

\begin{tabular}{|c|c|c|}
\hline Parcela & & 0,00 \\
\hline Ilumiação & & 0,00 \\
\hline PIS/COFINS & & 0,00 \\
\hline ICMS & 25,00 & 85558,40 \\
\hline
\end{tabular}

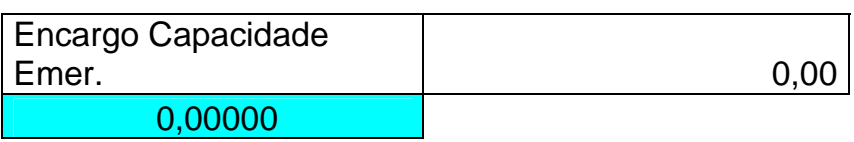




\title{
C. NOMENCLATURA UTILIZADA PARA A MACRO DE GERAÇÃO DE FATURAS.
}

\author{
Almoxarifado $=$ almox \\ Biblioteca Central do Estudante $=$ bce \\ Centro Comunitário $=\mathrm{cc}$ \\ CEFTRU $=$ ceftru \\ CEPLAN $=$ ceplan \\ $\mathrm{CESPE}=$ cespe \\ $\mathrm{FACE}=\mathrm{fa}$ \\ $\mathrm{FE} 01=\mathrm{fe} 01$ \\ FE03/05 $=$ fe0305 \\ $\mathrm{FM} / \mathrm{FS}=\mathrm{fmfs}$
}

Faculdade de Tecnologia $=\mathrm{ft}$

Garagem e Oficina = garagem

Geocronologia $=$ geocrono

ICC Norte $=$ iccnorte

$\mathrm{ICC} \mathrm{Sul}=\mathrm{iccsul}$

Instituto de Química = iq

Pavilhão Multiuso $1=$ multi1

Pavilhão Multiuso $2=$ multi2

Núcleo de Medicina Tropical $=\mathrm{nmt}$

Pavilhão Anísio Teixeira $=$ pat

Pavilhão João Calmon $=$ pjc 


\author{
Prefeitura $=$ pref \\ Reitoria $=$ reitoria \\ Restaurante Universitário $=\mathrm{ru}$ \\ $\mathrm{SG} 01=\operatorname{sg} 1$ \\ $\mathrm{SG} 09=\operatorname{sg} 9$ \\ $\mathrm{SG} 11=\operatorname{sg} 11$ \\ $\mathrm{SG} 12=\operatorname{sg} 12$ \\ Observatório Sismológico $=$ sis \\ RU Caldeiras $=$ rucald \\ Medição Geral = medgeral
}




\section{FATURA GERADA PELA MACRO RELATIVA AO MÊS DE MARÇO DO ALMOXARIFADO.}

\begin{tabular}{|c|c|c|c|c|}
\hline \multicolumn{5}{|c|}{ CICE - Comissão Interna de Conservação de Energia } \\
\hline $\begin{array}{r}\text { LOCAL: } \\
\text { MÊS FATURADO: }\end{array}$ & \multicolumn{4}{|c|}{$\begin{array}{l}\text { ALMOXARI FADO } \\
\mathrm{mar} / 2008\end{array}$} \\
\hline \multicolumn{5}{|c|}{ FORA DE PONTA } \\
\hline Descrição & Resgistrado & Faturado & Tarifa & $\begin{array}{l}\text { Valor } \\
(\mathrm{R} \$)\end{array}$ \\
\hline Demanda (kW) & 15 & 20 & 9,93 & 198,64 \\
\hline $\begin{array}{l}\text { Ultrapassagem } \\
(\mathrm{kW})\end{array}$ & 0 & 0 & 0,00 & 0,00 \\
\hline Consumo (kWh) & 3047 & 3047 & 175,04 & 533,34 \\
\hline & & & $\begin{array}{r}\text { SUB- } \\
\text { TOTAL*: }\end{array}$ & 689,16 \\
\hline \multicolumn{5}{|c|}{ PONTA } \\
\hline Descrição & Resgistrado & Faturado & Tarifa & $\begin{array}{l}\text { Valor } \\
(\mathrm{R} \$)\end{array}$ \\
\hline Demanda (kW) & 5 & 10 & 36,82 & 368,18 \\
\hline $\begin{array}{l}\text { Ultrapassagem } \\
(\mathrm{kW})\end{array}$ & 0 & 0 & 0,00 & 0,00 \\
\hline \multirow[t]{2}{*}{ Consumo (kWh) } & 163 & 163 & 280,83 & 45,71 \\
\hline & & & $\begin{array}{l}\text { SUB- } \\
\text { TOTAL*: }\end{array}$ & 389,67 \\
\hline *Incluindo desconto & & & TOTAL*: & $1.078,84$ \\
\hline
\end{tabular}

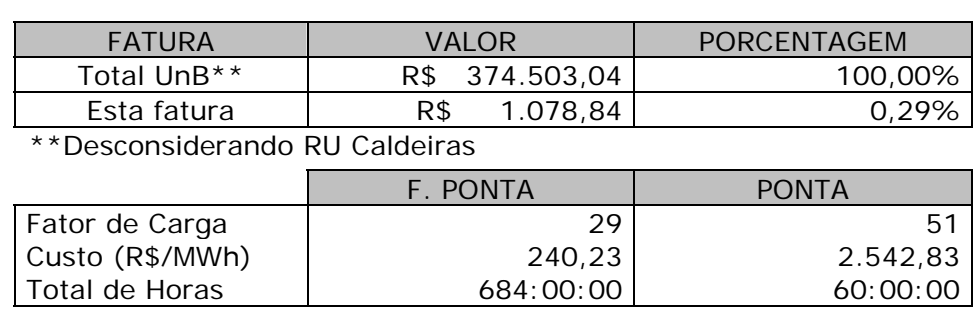

\begin{tabular}{|c|c|}
\hline \multicolumn{2}{|c}{ Histórico } \\
\hline MÊS/ANO & CONSUMO (kWh) \\
\hline $\mathrm{mar} / 2008$ & 3210 \\
\hline $\mathrm{fev} / 2008$ & 3089 \\
\hline $\mathrm{jan} / 2008$ & 3167 \\
\hline
\end{tabular}
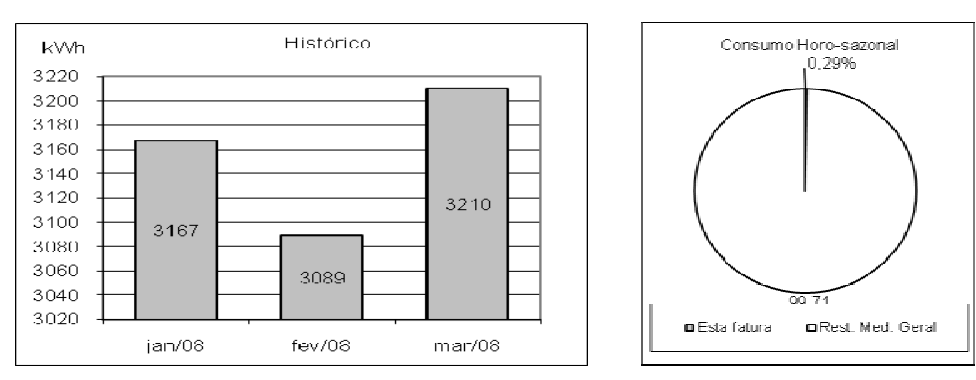